\title{
WestVirginiaUniversity
}

THE RESEARCH REPOSITORY @ WVU

Graduate Theses, Dissertations, and Problem Reports

2014

\section{Effect of biaxial and triaxial stresses on coal mine shale rocks}

Shrey Arora

Follow this and additional works at: https://researchrepository.wvu.edu/etd

\section{Recommended Citation}

Arora, Shrey, "Effect of biaxial and triaxial stresses on coal mine shale rocks" (2014). Graduate Theses, Dissertations, and Problem Reports. 5125.

https://researchrepository.wvu.edu/etd/5125

This Thesis is protected by copyright and/or related rights. It has been brought to you by the The Research Repository @ WVU with permission from the rights-holder(s). You are free to use this Thesis in any way that is permitted by the copyright and related rights legislation that applies to your use. For other uses you must obtain permission from the rights-holder(s) directly, unless additional rights are indicated by a Creative Commons license in the record and/ or on the work itself. This Thesis has been accepted for inclusion in WVU Graduate Theses, Dissertations, and Problem Reports collection by an authorized administrator of The Research Repository @ WVU. For more information, please contact researchrepository@mail.wvu.edu. 


\title{
Effect of biaxial and triaxial stresses on coal mine shale rocks
}

\author{
Shrey Arora
}

Thesis submitted to the

Benjamin M. Statler College of Engineering and Mineral Resources at West Virginia University

in partial fulfillment of the requirements for the degree of

\author{
Master of Science \\ in \\ Mining Engineering
}

Brijes Mishra, Ph.D., Chair

Christopher J. Bise, Ph.D., Keith A. Heasley, Ph.D., Yi Luo, Ph.D.,

Department of Mining Engineering

Morgantown, West Virginia

2014

Keywords: laminated rock, shale, biaxial test, cutter roof failure

Copyright 2014 @ Shrey Arora 


\section{ABSTRACT \\ Effect of biaxial and triaxial stresses on coal mine shale rocks \\ Shrey Arora}

High horizontal in-situ stresses and weak immediate roof rock have been a detrimental combination for underground coal mines in the eastern United States. Also, these conditions pose challenging ground control problems to researchers. One such problem, referred to by many names, is the "cutter roof," "kink failure," "gutter," or "pressure cutting." It is a compressional type failure of the roof, commonly observed in Appalachian underground coal mines with laminated roof rock.

The available literature concerning the aforementioned failure is limited in terms of our understanding of the mechanism underlying the failure. The fundamental research presented in this thesis is an attempt to provide a deeper understanding of the mode and/or mechanism underlying laminated rock failure. For this work, a special platen was fabricated and is capable of applying biaxial compressive stress on a specimen when the entire arrangement is used inside a uniaxial compressive loading device. The experimental set-up was further modified to apply a pseudo-triaxial compressive stress on the specimen.

Delamination of the laminated shale specimens was observed in the biaxial stress condition. Close monitoring of these tests revealed that the inner layers moved outward while the outer layers moved toward the unconfined area and warped before they failed. Limestone specimens tested under similar condition showed a different mode of failure. This test also showed that the failure mechanism observed in the laminated shale was unique and not an artifact of the experimental design. Lastly, the influence of lamination on the failure mode was observed to be less under triaxial stress conditions. Laminated shale specimens failed along conjugate shear planes along with compaction of rock under confinement. 


\section{ACKNOWLEDGMENTS}

The research compiled in thesis would not have been possible without the continuous support, excellent guidance, motivation, and critical input from my advisor, Dr. Brijes Mishra. I am indebted to him for his contributions towards the successful completion of this thesis and for providing an excellent research atmosphere.

I am thankful to the National Institute of Occupational Safety and Health for funding this research project. I would also like to express my appreciation to Alpha Natural Resources, Patriot Coal Corporation, and Murray Energy for providing samples for the experimental work mentioned in this study.

I would also like to extend my gratitude to my thesis committee members-Dr. Christopher J. Bise, Dr. Keith A. Heasley, and Dr. Yi Luo-for their insightful comments, suggestions, and important inquiries into my work. Their individual perspectives were instrumental in improving the quality of this research.

Special thanks to the late Mr. William J. 'Bill' Comstock (Lab Instrumentation Specialist at College of Engineering and Mineral Resources, WVU) for fabricating the biaxial platens used in this work. I will always remember his contributions. I am also thankful to Karla J. Vaughan and Karen Centofanti for their help in administrative matters.

I would also like to mention the names of my fellow lab mates-Xu Tang, Yuting Xue, and Christopher Newman-for keeping me engrossed in their intellectually stimulating discussions.

Finally, I dedicate this thesis to my parents and my siblings. Their unconditional love, support, and encouragement have played a pivotal role in shaping my personal and professional life. 


\section{TABLE OF CONTENTS}

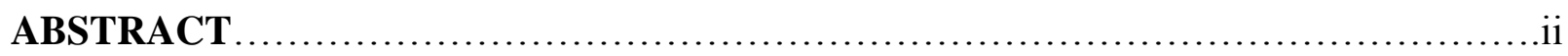

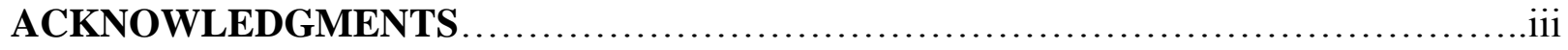

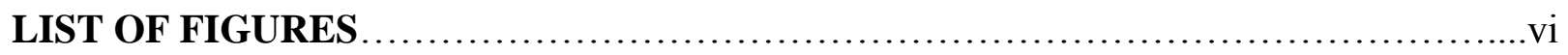

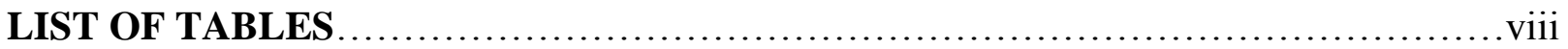

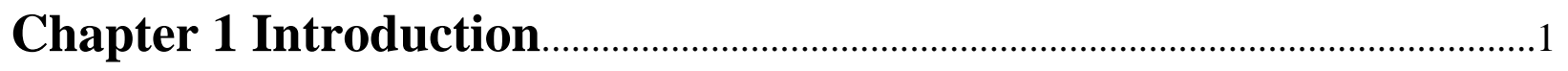

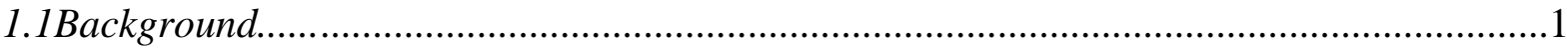

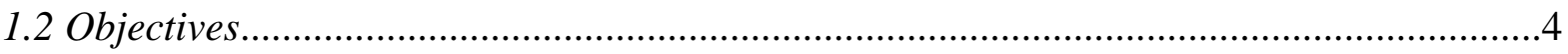

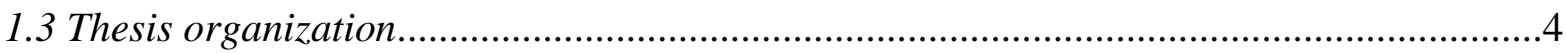

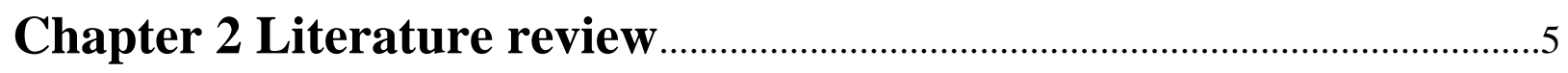

2.1 In-situ Horizontal Stress: Origin...........................................................................6

2.2 Horizontal Stress Trends in Eastern U.S. Coalfields.......................................................10

2.3 Roof fall Problem Associated with High Horizontal Stress..............................................11

2.3.1 Cutter roof.....................................................................................................11

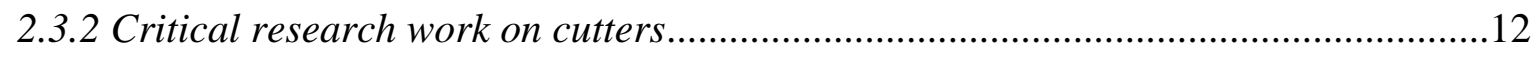

2.4 Summary of Literatures and Rationale for Present Research..........................................18

Chapter 3 Experimental Design and Set-Up..............................................19

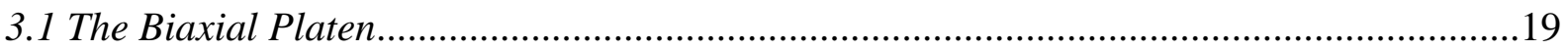

3.2 Modification of Biaxial for Triaxial Compression Test.....................................................22

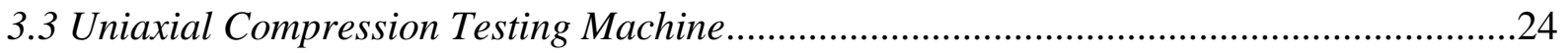

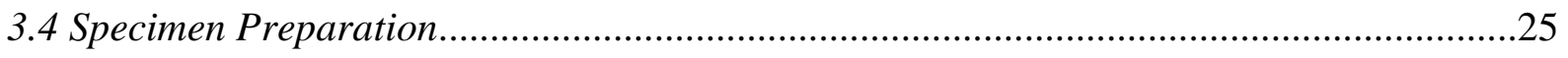

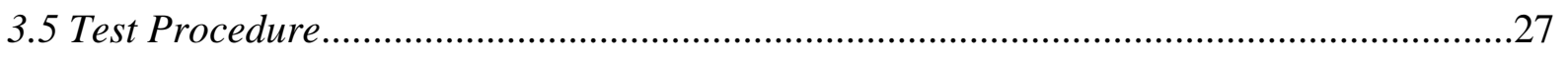

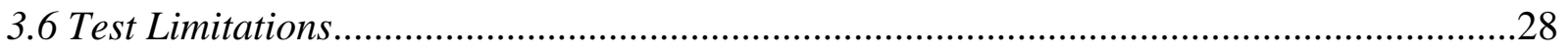

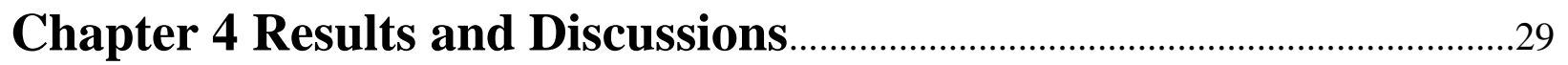

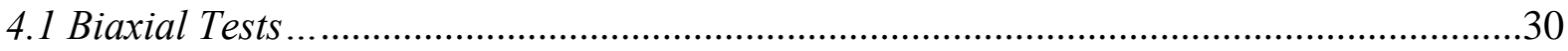


4.1.1 Effect of biaxial load on black shale specimens....................................................30

4.1.2 Effect of biaxial loading on the laminated shale specimen.......................................33

4.1.3 Effect of Biaxial load on limestone ......................................................................43

4.2 Effect of triaxial loading on the laminated rock ............................................................46

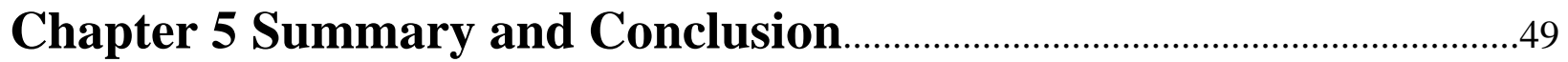 \\ REFERENCES}




\section{LIST OF FIGURES}

Figure 1.1 Decline of roof fall fatalities per million hours for underground bituminous coal mines, 1900 -

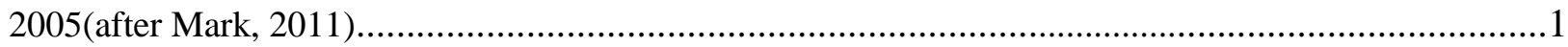

Figure 1.2 Leading geologic factors contributing to roof falls (after Bajpayee, et al. 2014)...................2 Figure 1.3 Stages of "cutter-roof" failure development (a) Initial stage of a cutter, (b) Small cutter type roof fall at a corner, and (c) Roof profile after a massive fall initiated by cutters (Gadde and Peng, 2005) 3

Figure 2.1 Roof fall rate in US coalfields from 2005 - 2006 (Molinda et al., 2008)...............................5

Figure 2.2 World stress map depicting the orientation of maximum horizontal stress (Source: http://dcapp3-14.gfz-potsdam.de/pub/stress_data/stress_data_frame.html...................................................... 8 Figure 2.3 Stress map of United States produced by WSM compared with coal field stress measurements

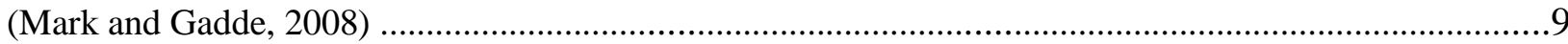

Figure 2.4 Horizontal stress orientation in eastern US coal fields. (Mark, 1991) ....................................10

Figure 2.5 Cutter roof failure with the exposed laminated roof and the bolts (Molinda and Mark, 2010)

Figure 2.6 Dimensions, geometry, and boundary condition of finite element model matched to geologic column (Kripakov, 1982) .14

Figure 2.7 Alternate roof support systems (Kripakov, 1982) 14

Figure 2.8 Percent of total lengths of clastic dikes and cutters in equal areas of 2,500 $\mathrm{m}^{2}$ (Hill and Bauer,

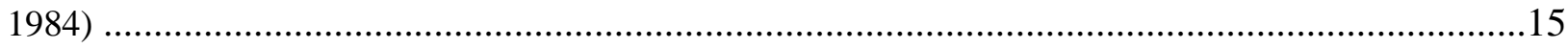

Figure 2.9 Finite element used by Su and Peng (1987) for their analysis......................................15 Figure 2.10 The extent of unstable roof with different material behavior model (solid dark line shows the outline and elements outside this line have safety above 1 or didn't yield). (Gadde and Peng, 2005).

Figure 3.1(a) Free body diagram of the device indicating the forces acting on the specimen (b) the shear device with a rock specimen (after Jumkis and Jumkis, 1975).... .20

Figure 3.2 (a) Stress acting on the roof of an entry (b) Stress distribution on specimen inside UCS testing machine. .20

Figure 3.3 CAD drawing of the biaxial platen showing the exact dimensions of the platen..................21

Figure 3.4 Fiberboard material was used for uniform distribution of load on an imperfect specimen............22

Figure 3.5 The ultra-force steel clamp (Grainger) .22 
Figure 3.6 Schematic view of experimental set-up with confinement...........................................23

Figure 3.7 Test set-up with biaxial platens and the c-clamp inside the test frame..............................23

Figure 3.8 Block Diagram of MTS uniaxial compression test system........................................24

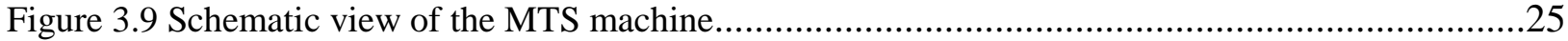

Figure 3.10 Finished specimens (d) prepared from rock chunks (a, b) and cylindrical specimens (c).

Figure 4.1 Pictures and plots of axial force against displacement of black shale specimens tested in biaxial platens.

Figure 4.2 The shaded side (magenta colored) of which the snapshots are presented and the orientation of laminations inside the device. .33

Figure 4.3 Separation of lamination observed at cutter location in a mine entry (Peng, 2007) .34

Figure 4.4 (a) (c) (e) (g) Load vs. displacement graph of laminated shale specimens tested in bi-axial compressive loading condition. (Encircled area depicting lamination separation). 36

Figure 4.5 (a) Markings on specimen to determine shearing of lamination under biaxial loading conditions

(b) Spray painted side of the specimen to determine tensile fracturing. .37

Figure 4.6 Position of failure mode indicators on the specimen with respect to biaxial device. .37

Figure 4.8 Post-test condition of shear movement indicator. .39

Figure 4.9 Post-test condition of tensile failure indicator (cracks in the white marked area represents the splitting or tensile failure developed during the test)

Figure 4.10 Separation of the laminated layer and crack development in the laminated specimen (Frames $1-12)$. .43

Figure 4.11 Post-test state of limestone specimens tested in the biaxial platens. .44

Figure 4.12 Plot of load against displacement of limestone specimens. . .45

Figure 4.13 Shear failure observed in triaxial compressive test on laminated shale specimen. .47

Figure 4.14 Axial force against displacement graph of the laminated shale specimens tested in triaxial compressive loading condition. 


\section{LIST OF TABLES}

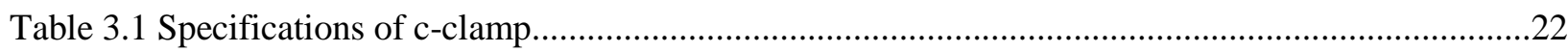

Table 3.2 Description of the specimen with the type of loading condition and number of specimens

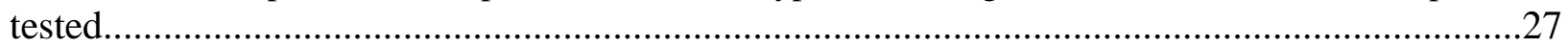

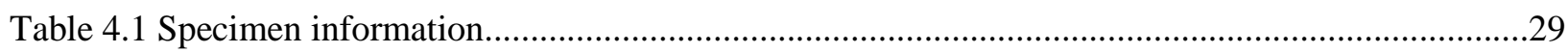

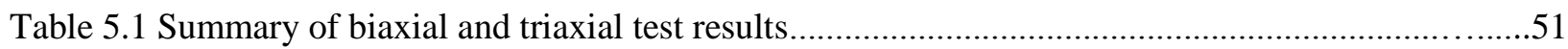




\section{Chapter 1}

\section{Introduction}

\subsection{Background}

The development of roof bolting in the late 1940s signaled the beginning of a new era in underground coal mining. As noted by Mark (2002), "Roof bolting has been the single most important technological development in the field of ground control in the entire history of mining." The coal mining industry was quick to embrace this technology as it brought about a considerable improvement in ground control safety, work efficiency, and coal production.

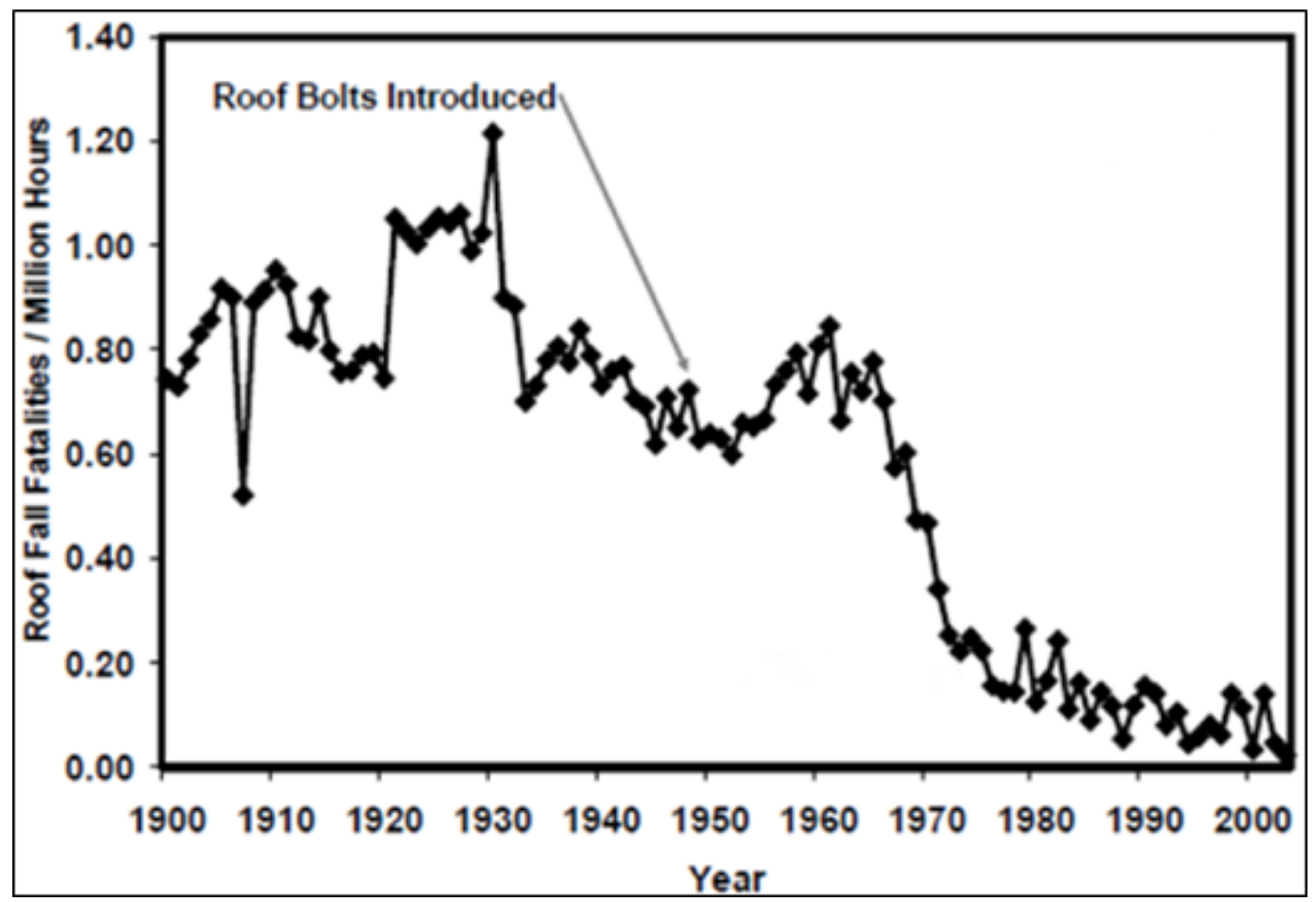

Figure 1.1 Decline of roof fall fatalities per million hours for underground bituminous coal mines, 1900 - 2005 (after Mark, 2011).

However, roof falls continue to pose a serious safety hazard for underground coal miners. According to Mark, et al. (2011), 400 miners or more are injured every year because of falls of roofs exposed between supports. This should serve us as a reminder that there is no room for complacency of ground control engineers. It in fact reminds us that developing new 
technologies might not be the only solution to this problem. It is imperative that rock behavior is completely understood for ensuring the success of new roof support technology and for the development of a robust roof fall control technology.

Bajpayee et al., (2014) investigated the geologic factors contributing to roof falls. Based on the well-documented narratives of mine operators, 1,825 non-injury roof falls from 1999 through 2008 were analyzed. Their study revealed that a majority of roof falls occur in laminated roofs (consisting of stack rocks, slate, laminated shale, etc.).

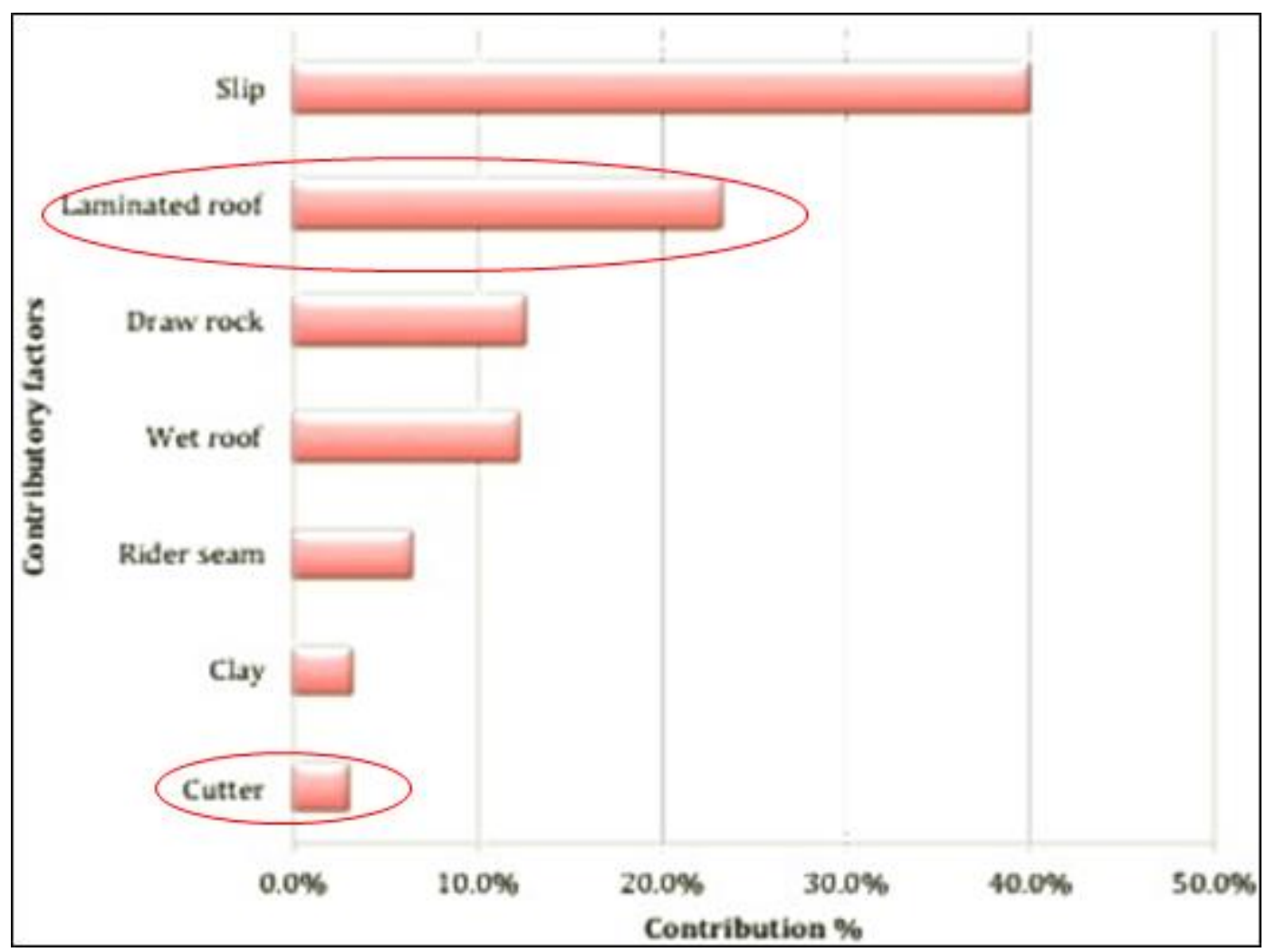

Figure 1.2 Leading geologic factors contributing to roof falls (after Bajpayee, et al. 2014).

These formations are found deposited in a nearly horizontal direction in the immediate roof and are weak along the bedding or joint material. The presence of high horizontal in-situ stresses along the direction of discontinuities deeply aggravates the roof fall problem in these bedded rocks. "Delamination" is a common phenomenon under these circumstances, in which laminated rock separates into thin, weak beams (Esterhuizen and Bajpayee, 2012) capable of buckling under the given horizontal loading condition. This greatly affects the structural integrity of the roof rock, reducing overall strength and facilitating fracture development. 
Another unique phenomenon observed in laminated roof rock is "cutter roof," also known as "kink failure," "gutter," or "roof gutter," and "pressure cutting." It is a compressional type failure of roof (Mark, 1991), commonly observed in Appalachian underground coal mines (Su and Peng, 1987). In this case, a stepwise initiation of failure was commonly observed in mines. In the first stage, small fracture develops at the corner of the entry. This fracture then grows in size and small-localized failure is observed. Subsequently, the failure propagates through the upper strata until it comes across a more competent stratum or when it is beyond the roof bolt horizon. At this stage, the failure then travels across the entry and the entire roof collapses. The entire sequence is shown in Figure 1.3.
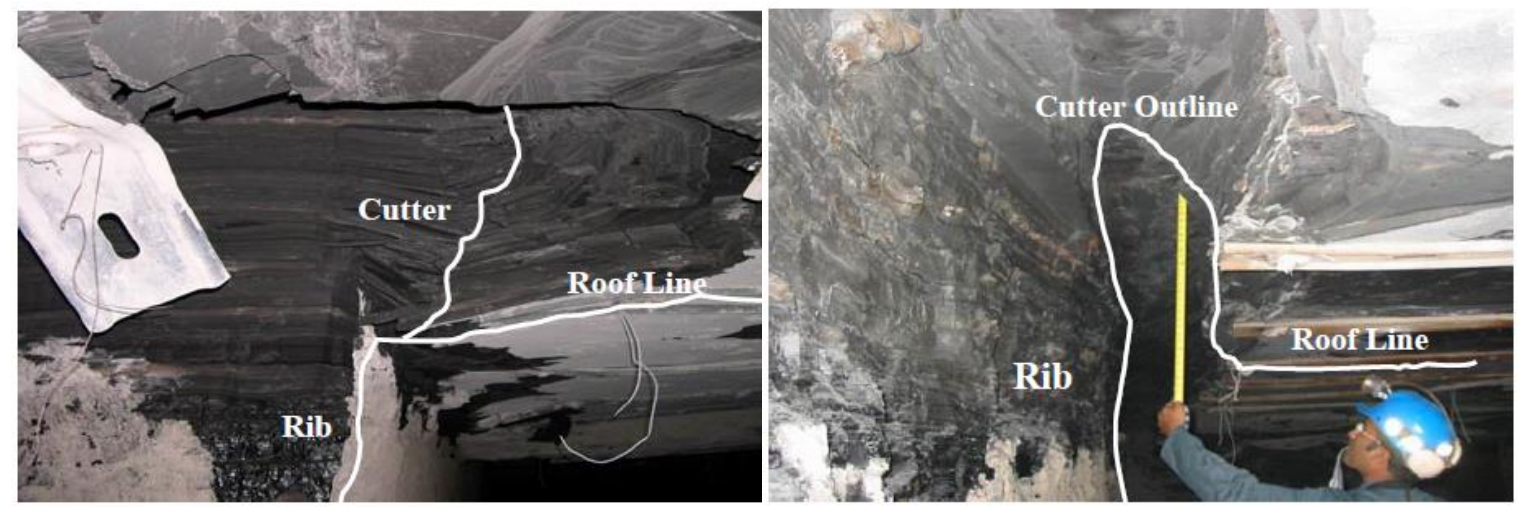

(a)

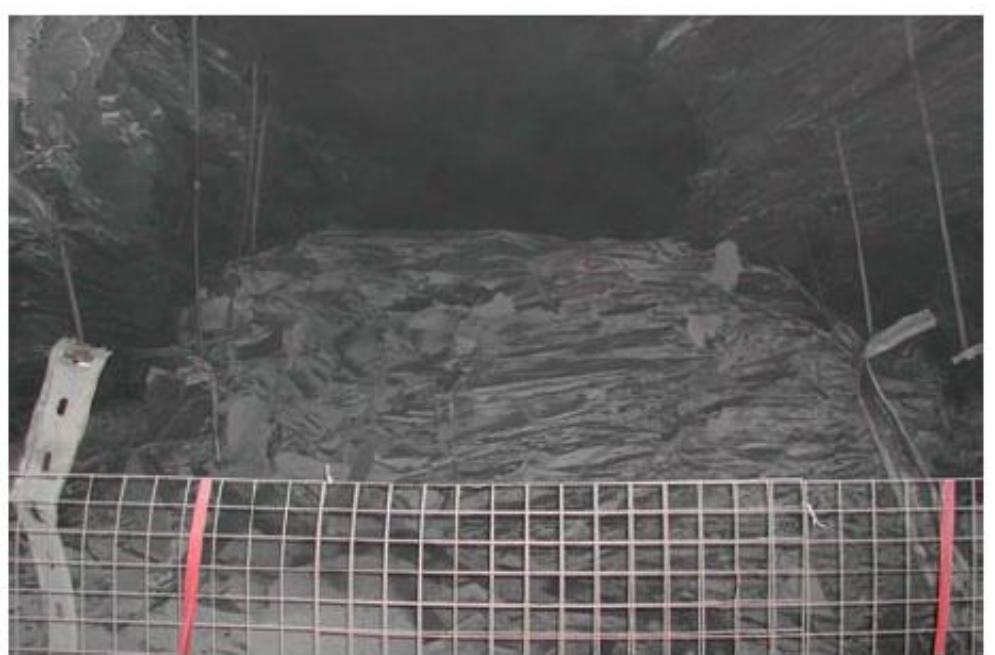

(b)

(c)

Figure 1.3 Stages of "cutter-roof" failure development (a) Initial stage of a cutter, (b) Small cutter type roof fall at a corner, and (c) Roof profile after a massive fall initiated by cutters (Gadde and Peng, 2005) 


\subsection{Objectives}

The primary objective of the current research was to study the behavior of laminated roof rock, particularly laminated shale rock, under different loading conditions. The tests were performed in a unique platen that applied biaxial load to the laminated and non-laminated specimens. Following are the sub objectives:

1. Investigation of the effect of biaxial stress on shale with no distinct lamination.

2. Investigation of the effect of lamination on the failure mode of the specimen.

3. Understanding the movement and failure of the rock through real-time recording of the test.

4. Investigation of the effect of different rock type on the mode of failure.

5. Finally, investigation of the effect of triaxial stress on laminated shale specimen.

\subsection{Thesis Organization:}

This thesis is organized into five chapters. Chapter 2 summarizes the available literature concerning horizontal in-situ stress (its origin and orientation in eastern U.S. coalfields), related problems in underground coal mines, and research aimed at analyzing and solving these problems. Chapter 3 describes in detail the experimental set-up used in this thesis. Chapter 4 enlists all the results obtained from laboratory experiments and its analysis and finally, Chapter 5 summarizes the important results and conclusions of this research and makes future recommendations. 


\section{Chapter 2}

\section{Literature review}

In this chapter, a quick review of the existing in-situ compressive horizontal stresses in the Appalachian region and Illinois basin is provided. These two regions are the prime focus of this literature review as the underground mines located here have been known to be plagued by severe ground control problems (roof fall, floor heave, and rib slabbing) over the years (Figure 2.1). This will be followed by how researchers have linked the occurrence of some of the ground control problems like directional roof falls and "kink roof" or "cutter roof" to the regional horizontal stresses and other factors in light of some mine case studies and numerical modeling. Finally, the rationale for undertaking the research presented in this thesis will be provided based upon the relevant scientific literature compiled in this section.

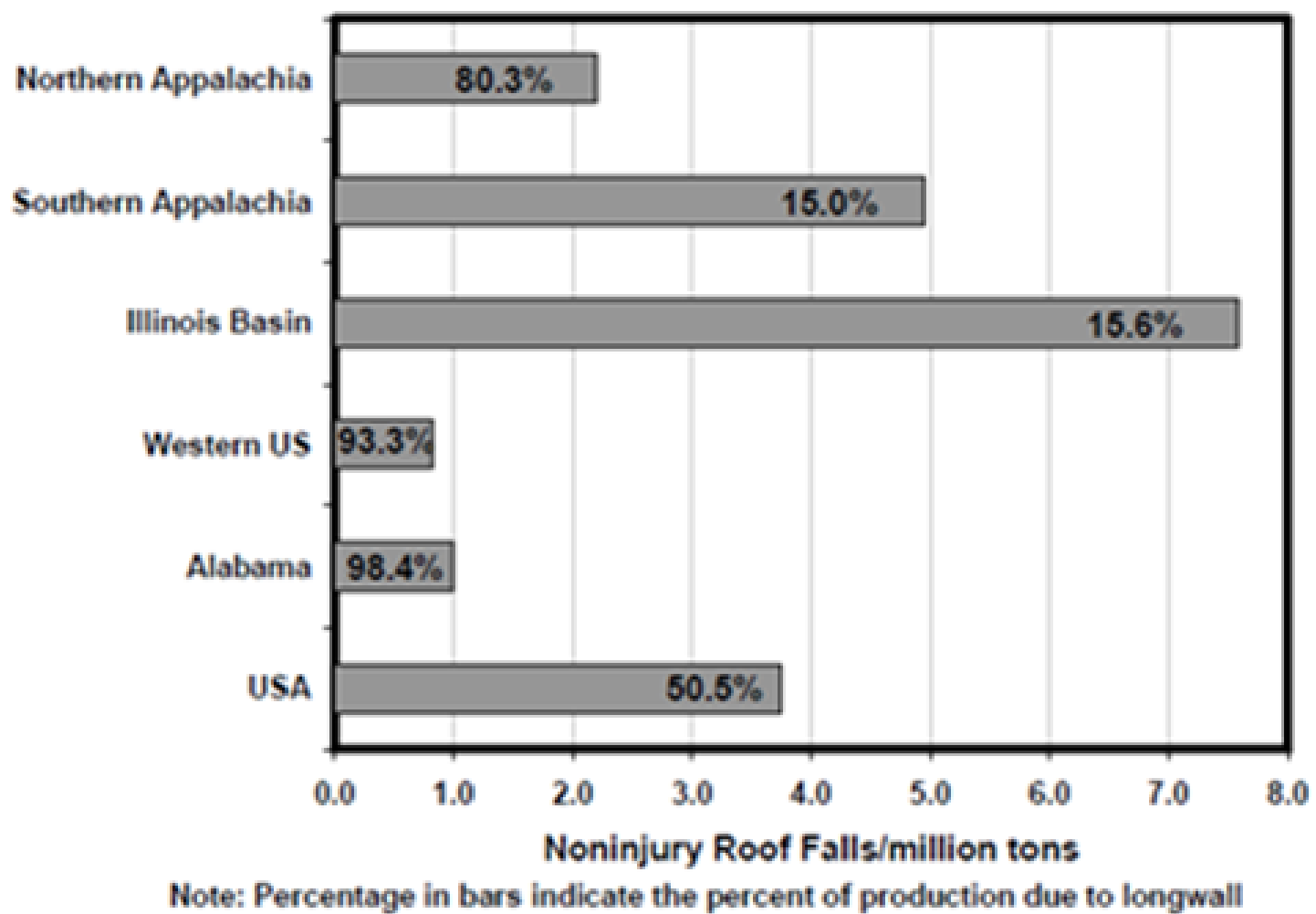

Figure 2.1 Roof fall rate in U.S. coalfields from 2005-2006 (Molinda et al., 2008) 


\subsection{In-situ Horizontal Stress: Origin}

The cause of ground control problems (such as floor heave and cutters) in mines with shallow overburden remained elusive to the researchers of the early $19^{\text {th }}$ century, in the absence of other geologic factors. Aggson and Curran (1978), refer to a report dated April 1929, by James P. Keatley of the West Virginia State Department of Mines, on the persistent floor heave problem in the Glen Rogers mine operating in the Beckley coalbed. The report ruled out any relationship of groundwater, gas, and overburden thickness (600 to $1300 \mathrm{ft}$ ) to floor heave. And in conclusion, made a very critical observation: "A statement in brief as to the cause (of floor heave) would be that an undetermined natural condition doubtless augmented by former and present mining methods causes the bottom to heave."

Numerous in-situ stress measurements by various investigators all over the world in the latter half of the 19th century provided concrete evidence that there exists a biaxial horizontal compressive stress field. And, coal mine ground control researchers (Dahl and Parsons, 1972; Aggson and Curran, 1978; Ingram and Molinda, 1988; and Su and Hasenfus, 1995) came to the same conclusion; and their field measurements helped in better understanding the "undetermined natural condition" put forward by Keatley in 1929. Consequently, attempts were also made at determining the origin or source of observed and measured geologic lateral stresses (Mark and Gadde, 2008). Two of the earliest theories were:

- Poisson's effect: a model predicting the value of horizontal stress to be a function of Poisson's ratio, and

- Lithostatic stress state: postulating a hydrostatic condition within the earth's crust with all the three principal stresses to be approximately equal.

Later, researchers (Mark and Gadde, 2008; McGarr, 1988; Hoek, 2007) pointed out the shortcoming in these theories:

- Cases where horizontal stresses exceeded vertical stress could not be explained using the above the theories,

- No explanation for the biaxial nature of horizontal stresses, and 
- One of the assumptions of these theories is that lateral deformation is kept constant. This appears unrealistic as observations indicate horizontal movement inside the earth's crust in response to applied loads.

Today, the theory proposed by the group of scientist working on the World Stress Map (WSM) Project in 1970, for the International Lithosphere Program, is widely accepted. They proposed that the present-day 'tectonic stresses' (Zoback and Zoback, 2007) are the primary categories of forces responsible for the existing state of lithospheric stress (the secondary forces being the 'induced stresses' (Zoback et al., 1989) caused by ground surface topographic effects, anisotropic mechanical properties of rock, erosion, and man-made excavations).

To explain it further, the "plate tectonic theory" states that the lithosphere of the earth is composed of a number of individual continental plates that float and drift on the softer mantle below it. The relative movement of plates generates tremendous dynamic forces at their boundary, which is transmitted throughout their interior. Scientists working on WSM were able to monitor this phenomenon using various indicators (Zoback and Zoback, 2002), including: (a) earthquake focal mechanism, (b) geologic stress indicators (orientation of dikes and fault slip data), and (c) in-situ stress measurements (wellbore breakouts, drill induced fractures, borehole slotter, overcoring, and hydraulic fractures). Discussion of these indicators is beyond the scope of this thesis.

With the help of the indicators mentioned above, a map was released showing the plate boundaries, horizontal stress orientation, and measurement techniques at each data collection site (Figure 2.2). It is important to note here that these measurements are valid and indicative of the stress field at depths greater than $100 \mathrm{~m}$ (Zoback and Zoback, 2002). Stress measurements at shallow depth $(<100 \mathrm{~m})$ were influenced by "induced stresses" (discussed earlier) and were excluded from the database of WSM project (Zoback, 1992). Mark and Gadde (2008) raised a very pertinent question on this exclusion: "Since most underground coal mining takes place within several hundred meters of the surface, it is legitimate to ask how relevant the WSM is to underground coal mining." Their study indicated that $75 \%$ of the past in-situ measurements in the eastern U.S. coalfields were in agreement with the ENE horizontal stress orientation 
identified by the WSM (Figure 2.3). However, this was not the case for the mines located in the western U.S. (Colorado, Wyoming, and New Mexico).

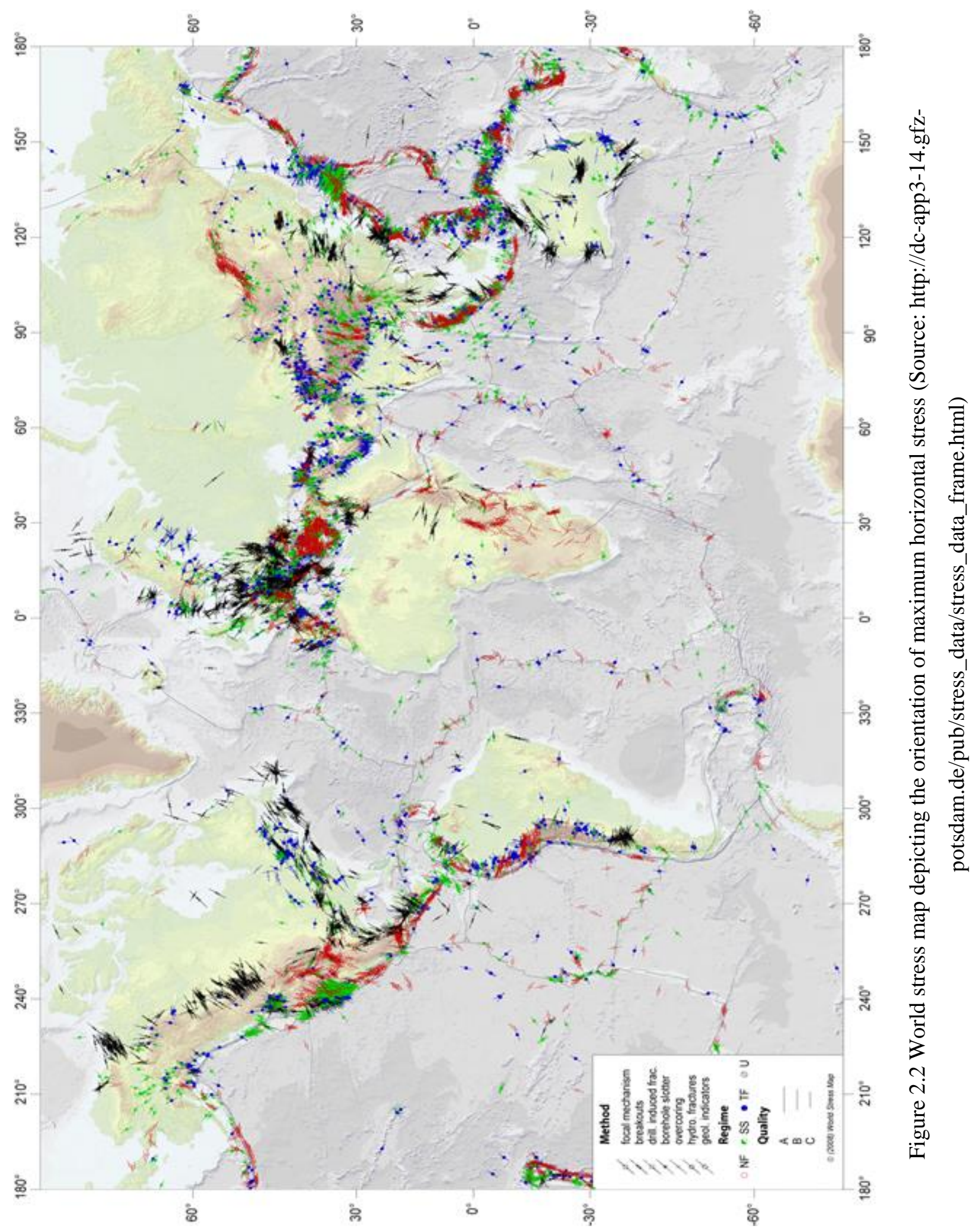




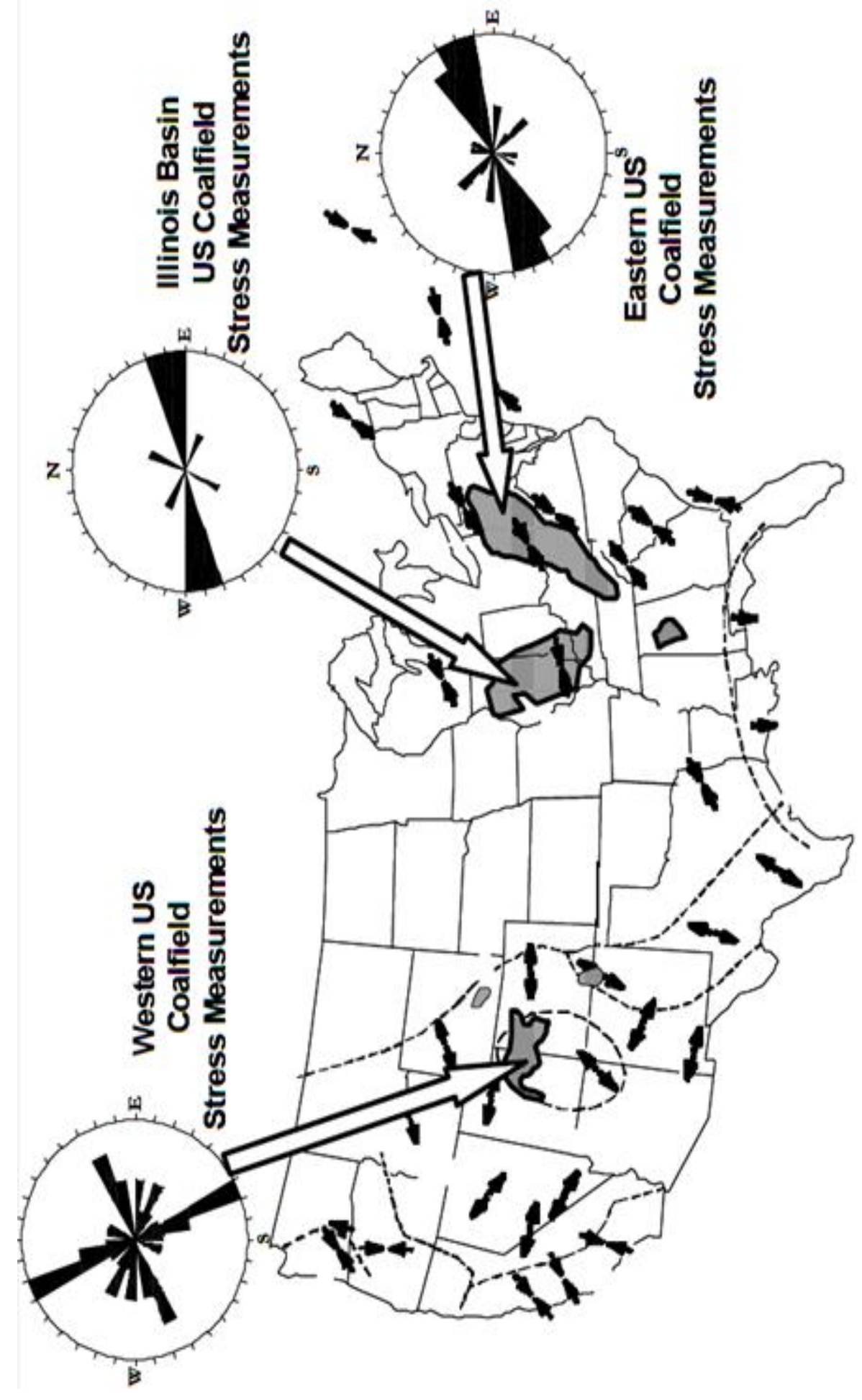

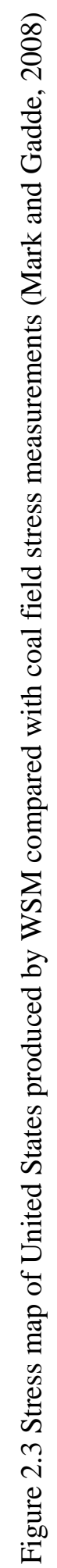


The next section of this literature review will take a closer look at the lateral stress measurements carried out in U.S. coal mines, particularly in the eastern part of the country.

\subsection{Horizontal Stress Trends in Eastern U.S. Coalfields}

According to Mark (1991), in-situ stress measurements at 25 underground coal mine sites in the eastern U.S. indicate E-NE horizontal stress orientation. Sixty-seven percent of the measurements conducted at the Appalachian and Warrior coal basin found the orientation to be between N80E and N50E. At the Illinois basin, a total of seventy five percent of the measurements found the stress direction had deviated towards E-W by $15^{\circ}$ (Figure 2.4).

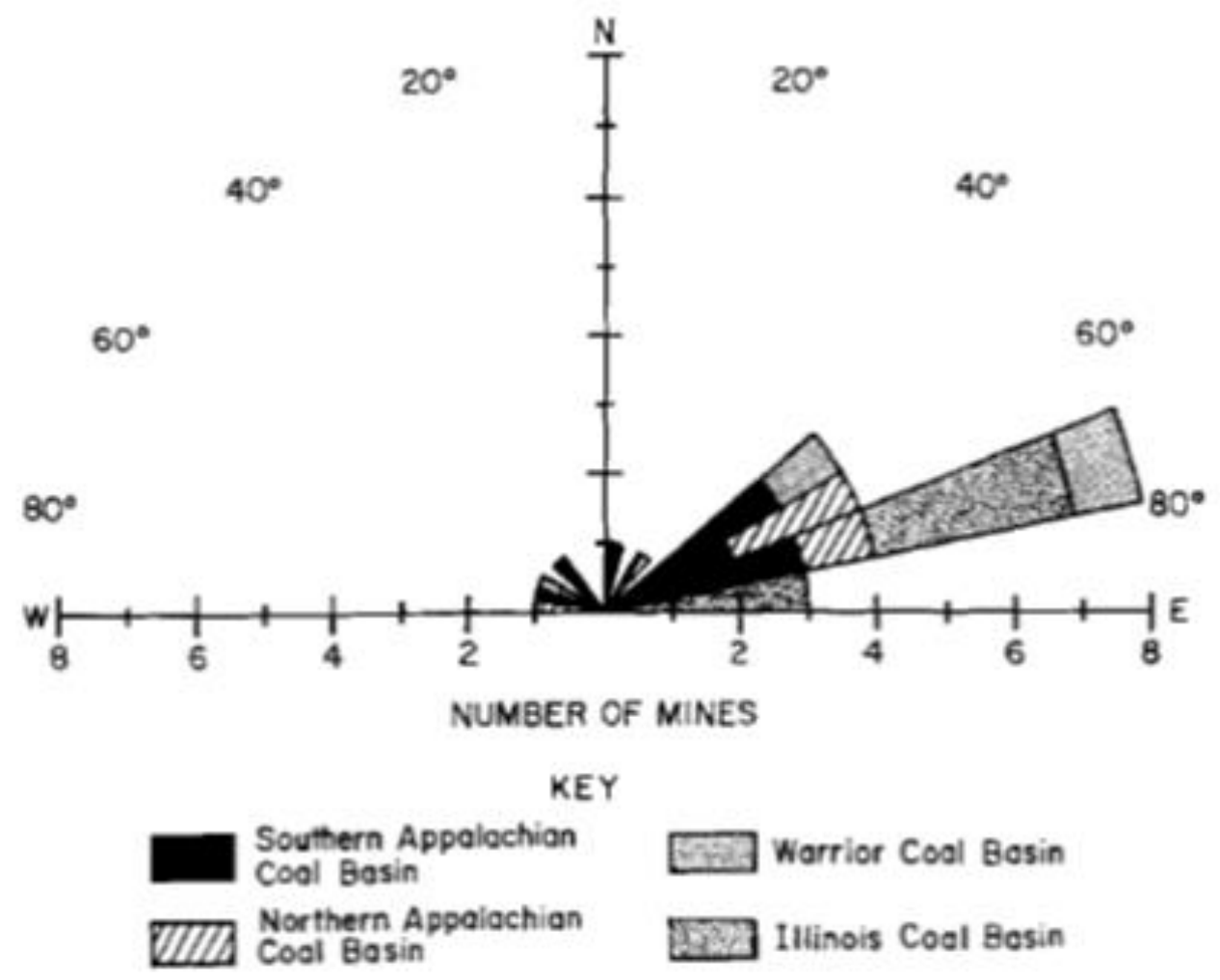

Figure 2.4 Horizontal stress orientations in eastern US coal fields (Mark, 1991).

Dolinar (2003) examined the variation of horizontal strain magnitude at 37 sites in the eastern and midwestern United States. He concluded that the measurements suggest that the eastern U.S. can be divided into two distinct high and low strain zones. The high strain zones comprise the Beckley coal seam and the Central Appalachian region only. The remaining eastern 
U.S. were found to be in the low strain zone, except for the Central Appalachian region, where the distinction remained inconclusive.

\subsection{Roof Fall Problem Associated with High Horizontal Stress}

Based on earlier sections of this thesis, the review of scientific literatures has established that the earth's crust experiences horizontal stresses, which are primarily tectonic in nature. This sub-section will dig deep into the research pertaining to the effects of these lateral stresses on the stability of an underground coal mine. The problem of "cutter roof failure" will be discussed in detail with an emphasis on laminated immediate roof rock as the common denominator in these cases.

\subsubsection{Cutter roof}

"Cutter roof," as discussed in the opening chapter of this thesis, is a compressional type of failure, mostly found in underground mines with laminated roof rock and which are experiencing severe horizontal stresses. It is a failure in the roof that typically occurs at the roofrib intersection and progressively grows until the entire roof falls. It should be noted here that not all cutters are precursors to roof falls. The period between the onset of fracture at the entry corner until the complete failure of the entry roof is quite unpredictable. It can be up to a few weeks or months, and sometimes the fracture stops growing completely after it begins.

Considerable research has been performed in the past aimed at determining causal factors of cutter roof and subsequent failure. Studies have indicated that apart from the presence of high horizontal in-situ stresses, factors such as rock type (strength and stiffness) (Su and Peng, 1987), geologic anomalies (clay veins, coal cleats) (Hill and Bauer, 1984; Iannachione et al., 1984; Bauer, 1990), mine surface relief, etc. could also control the formation and development of cutters.

Attempts have also been made in the past to simulate cutter roof failure using numerical modeling (continuum, boundary element, and discontinuum modeling). The use of strainsoftening type of constitutive behavior of materials (Gadde and Peng, 2005), sequential excavation of the mine entry (Ray, 2009), appropriate in-situ horizontal stress and orientation has 
helped replicate some of the crucial aspects of this type of roof failure. They include: progressive nature of failure, inconsistent spatial distribution, and location inside an entry (roof-rib intersection).

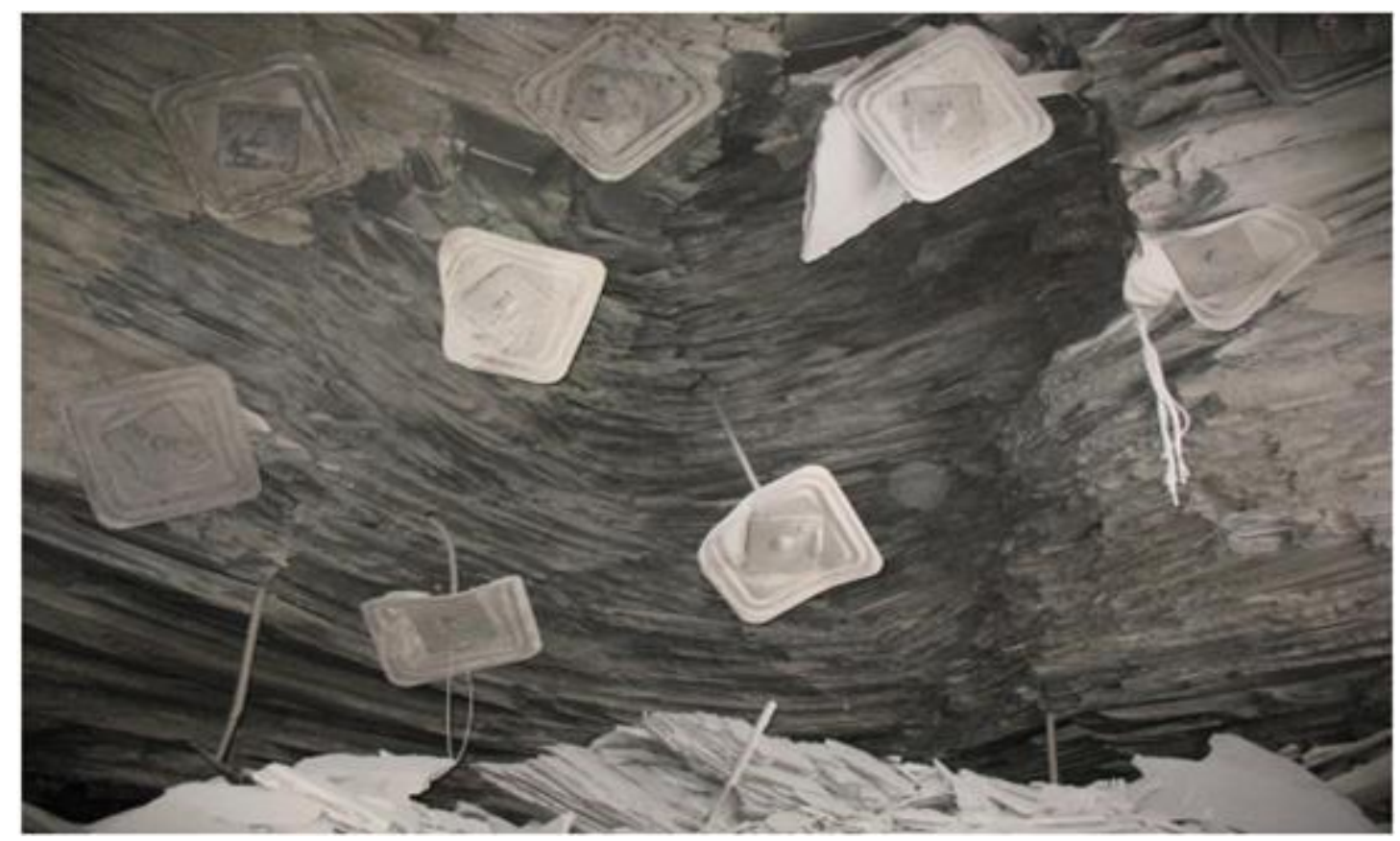

Figure 2.5 Cutter roof failure with the exposed laminated roof and bolts (Molinda and Mark, 2010)

\subsubsection{Critical research work on cutters}

Perhaps the earliest documented scientific literature on "cutter roof" dates back to 1948 by Rolf W. Roley. He used term "pressure cutting" in his article to describe an unusual type of failure occurring at many underground mines in Illinois. The failure occurred in a particular section of a mine where timber supports that were installed (which had proved successful elsewhere) completely failed without any warning signs. Other common characteristics were:

1. Failure became recognizable by the presence of an "advancing crack in the roof, near the center or against the rib of the place, moving forward with the advancing face."

2. During the stage between initiation of failure and roof fall, the roof showed significant downward bend. It appeared as a force much greater than just the weight of the roof alone was responsible for this observation.

3. A significant quantity of gas was also found in these areas and was considered one of the causal factors. 
4. Lateral pressure was also concluded to be a reason behind this failure as a "zone of squeeze was observed along the rib where the laminated roof appeared to be jammed together."

Dahl and Parson (1972) published their ground control studies at Consolidation Coal Co.'s Humphrey No. 7 mine. The study was aimed at determining the geologic and geometrical factors that could be responsible for a severe roof fall condition at any location inside the mine. In particular, they investigated the north-south roof fall (cutter roof failure) trend in rooms and entries of Humphrey No. 7 mine and in the northern West Virginia-southwestern Pennsylvania coal mining areas. Their investigation included:

1. Pillar deformation measurement: to study whether anisotropic pillar stiffness is responsible for the concentration of high shear stress at the roof-rib intersection.

2. In-situ stress measurements: hydrofrac stress measurement technique was used to quantify the effect of lateral stress.

3. Finite element numerical modeling: (a) to assess the effect of existing stress regime on the mining condition, (b) to study the effect of varying room and pillar size on overall stability.

Results of their study indicated the presence of a biaxial horizontal stress regime with the maximum horizontal principal stress two to three times the overburden stress. It was also inferred that the presence of such high lateral stress orientated in an east-west direction caused the north-south failures. Among all the identified geologic and geometric factors, only room width was declared statistically important based on numerical analysis. This study is remarkable because it brought about the change in orientation of most of the longwall mines in the Pittsburgh seam. (The general directional trend of mines now is east-west.)

Kripakov (1982) also analyzed previously proposed roof control techniques at Kitt Mine using finite element models (Figure 2.6). His investigation included parametric analysis of entry width and horizontal slot dimensions on maximum shear stress observed at the entry corner; the effect of pillar softening or induced pillar yielding and the effect of artificially inducing hard and soft zones above the pillar were also evaluated. Based on this study, it was recommended to mine wider entries and narrow pillars and to mine horizontal slots at the immediate roof line (Figure 2.7) 


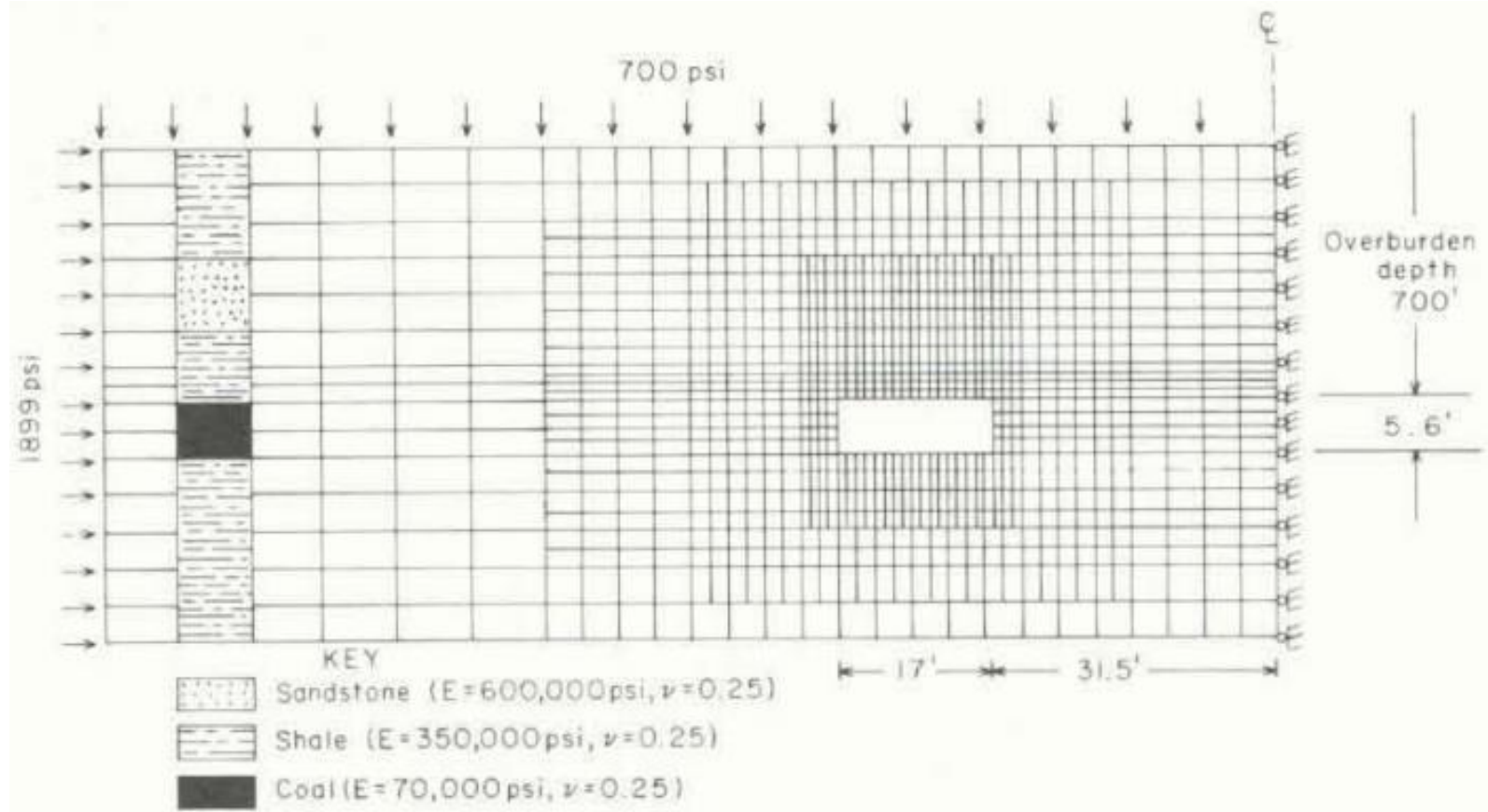

Figure 2.6 Dimensions, geometry, and boundary condition of finite element model matched to geologic column (Kripakov, 1982)

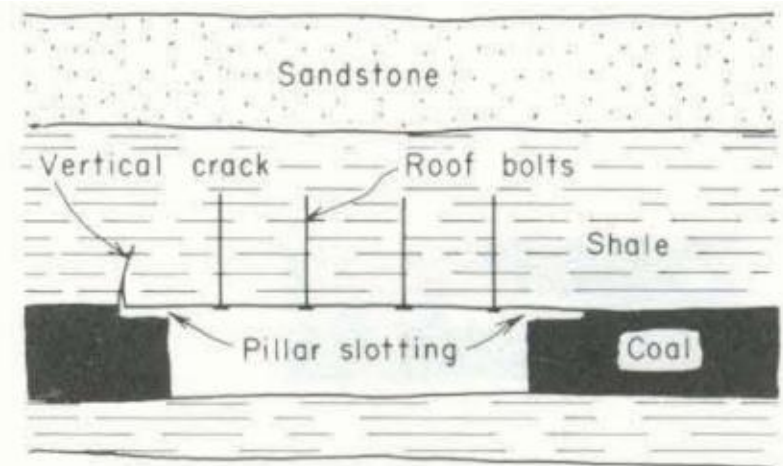

A. EFFECTS OF SLOTTING ON CRACK INITIATION

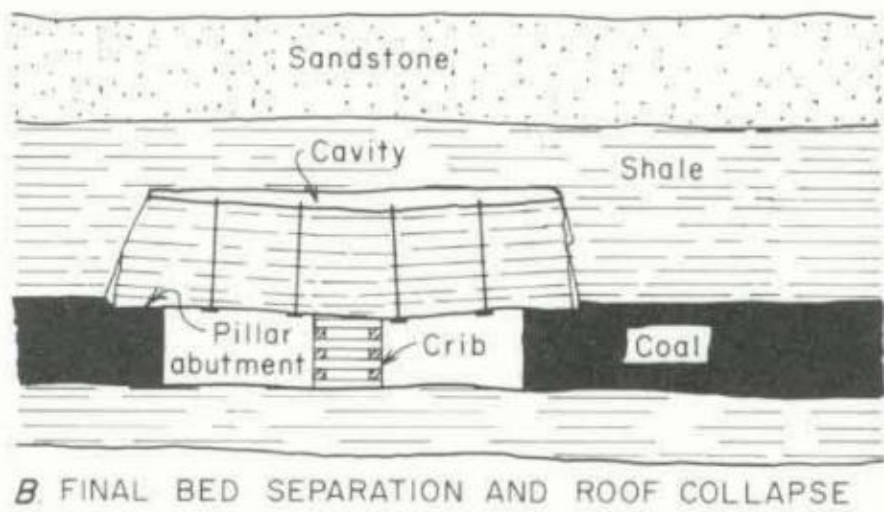

Figure 2.7 Alternate roof support system (Kripakov, 1982) 
The Bureau of Mines report by Hill and Bauer (1984) investigated the role of clastic dikes (clay veins) in the formation of cutter roof failure. In-situ measurements revealed elevated levels of roof loading at places where the dikes intersected the ribs and that the roof strata was behaving like a cantilever beam. They also showed a strong correlation between the lengths of these dikes with the length of cutters (figure 2.8). Based on their study, it was recommended to stagger the crosscuts and installation of cribs and trusses immediately after mining.

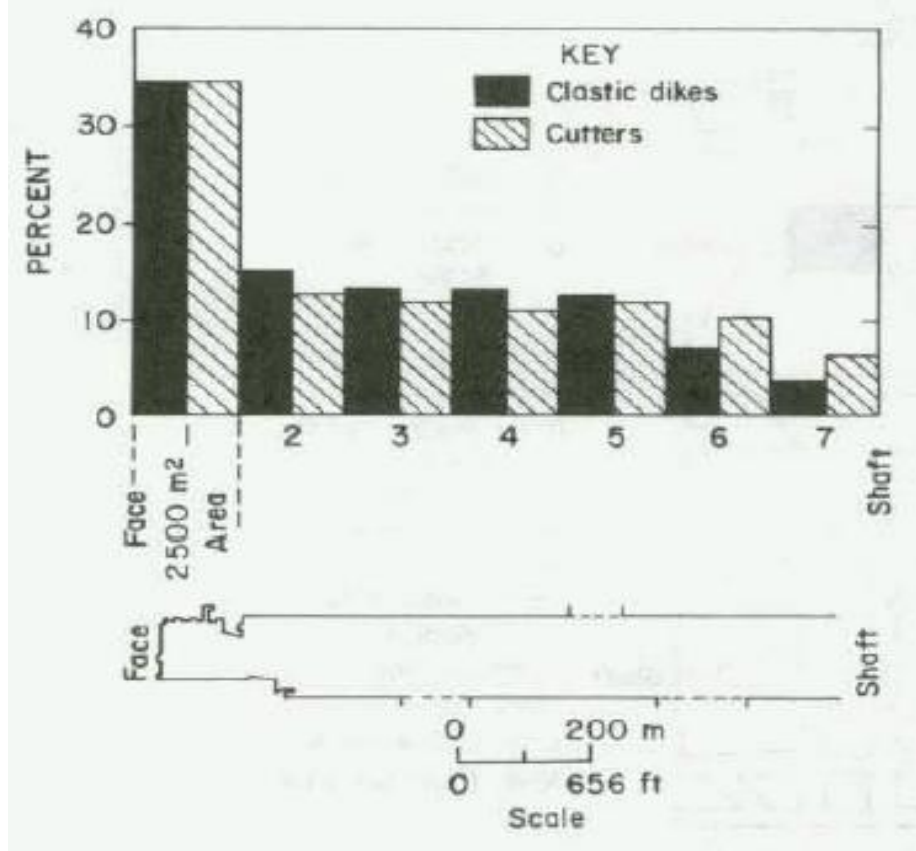

Figure 2.8 Percent of total lengths of clastic dikes and cutters in equal areas of 2,500 $\mathrm{m}^{2}$ (Hill and Bauer, 1984)

Su and Peng (1987) used finite element models extensively to determine the "intrinsic" mechanism responsible for cutter roof failure. 

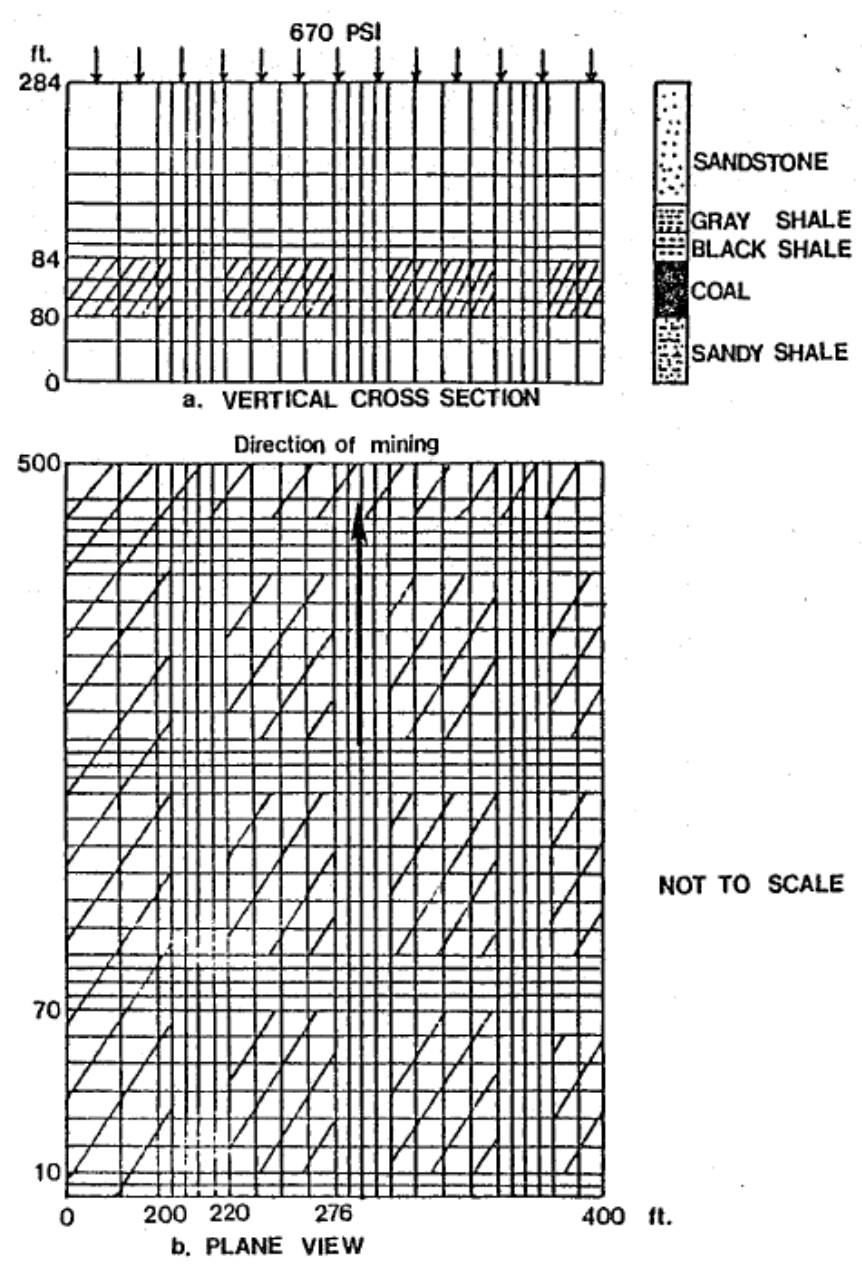

Figure 2.9 Finite element model used by Su and Peng (1987) for their analysis.

They conducted a parametric study in order to find out all possible factors responsible for cutter roof failure, including, for example: effect of high vertical stress, excess horizontal stress, relative stiffness between coal and its immediate roof, large topographic relief, bed separation, gas pressure, and geologic anomalies (clastic dikes).

The results of their numerical modeling showed that vertical stress controlled the behavior of the immediate roof at the entry corner. On the other hand, the direction and magnitude of horizontal stress affected the nature and location of cutter roof failure. Important recommendations based on this study were:

- Adoption of large pillars while keeping the same opening width,

- Adoption of smaller entries while keeping the same pillar width,

- Pillar softening, 
- Reorientation of the entries to a direction $45^{\mathrm{O}}$ from either the maximum or the minimum horizontal principal stresses,

- Installation of angle roof bolts or longer bolts near the ribs,

- Reorientation of the crosscuts while maintain the same entry direction,

- Installation of roof trusses and cribbing,

- Application of yield pillars, and

- Application of caving entries.

Gadde and Peng (2005) used a strain-softening constitutive model in their numerical analysis. This was done primarily to replicate the load-shedding mechanism observed at cutter locations and make the analysis more realistic. They also included the cutting sequence or entry and crosscut development sequence for the same reason. The main conclusion of their investigation was that the failure profile and extent of failure as observed in their models were closer to the observations at a cutter roof location (figure 2.10).

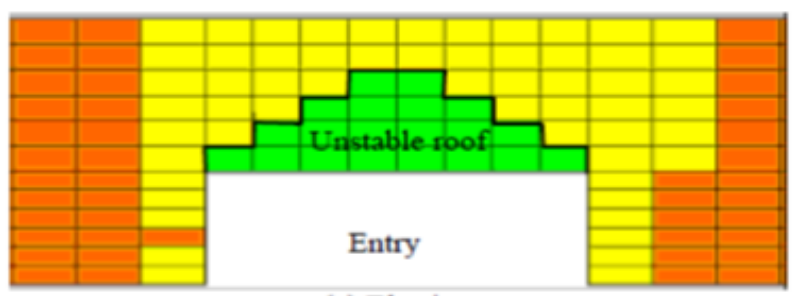

(a) Elastic

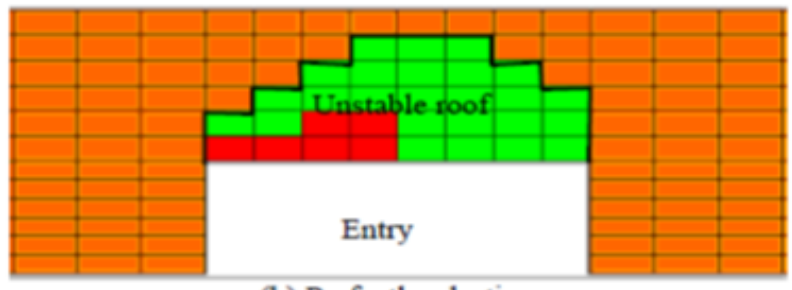

(b) Perfectly-plastic

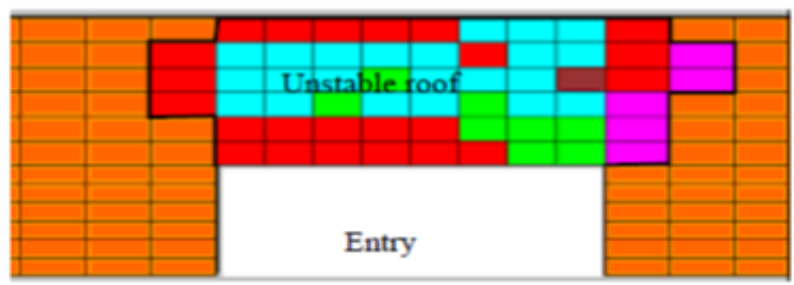

Figure 2.10 The extent of unstable roof with different material behavior model (solid dark line shows the outline and elements outside this line have safety above 1 or didn't yield). (Gadde and Peng, 2005) 


\subsection{Summary of Literatures and Rationale for Present Research}

By carefully reviewing the past research on cutter roof, it is concluded that:

1) Eastern United States coalfields experience horizontal stress, which is generally higher than the vertical stress. This relatively high lateral stress coupled with a laminated roof stratum pose safety hazards to miners. Roof falls may also lead to disruption in production and economic losses.

2) Prolific and commendable work focusing on the causes and control of cutters has been performed in the past. Investigation techniques consisted of stress measurement and numerical modeling.

3) Numerical modeling parameters were derived from laboratory tests (test on NX core size specimens) and field measurements. It remained inconclusive whether the behavior of the laminated rock was considered in these models or not.

4) It appears that no laboratory experiments have been performed to replicate the failure of laminated rock in cutter roof failure. 


\section{Chapter 3}

\section{Experimental Design and Set-Up}

Cutter roof is a unique failure created by the combination of stresses, rock formation, and mining sequences. As mentioned earlier, high horizontal stresses were found to augment the failure process. During the onset of the failure process as shown in Figure 1.3 (a), the laminations do not show any bending. However, as the failure progresses inside the roof, the bending of the laminated outer layers is clearly visible. It is still unknown whether the failure occurs first and then the laminated layer moves towards the entry, or vice-versa, or they occur at the same time. To find this unknown, true-triaxial equipment would be ideal as the load on the specimen can be independently controlled and various stress paths can be designed to create the failure as observed in the rock mass. However, such equipment is limited in availability and beyond the financial scope of the current research. Therefore, the author designed a biaxial platen, used in this thesis for investigating the failure and the movement of the laminations. With the help of industrial clamps, the device was also used as a pseudo-triaxial loading system.

\subsection{The Biaxial Platen}

The biaxial platen was designed and fabricated out of mild steel at West Virginia University. It was designed by modifying the direct shear device developed by Jumkis (1975). Figure 3.1 shows both the free body diagram of the device and the forces that act on the specimen during testing and the actual device. In Figure 3.1 (a), "P" is the force acting on the top of the platen, "N" is the component of the load acting normally to the specimen, and " $\mathrm{T}$ " is the tangential load acting on the upper part of the specimen. In equilibrium conditions, reaction forces will act on the lower part of the specimen, creating two shear forces that will fail the specimen in shear. The bottom platen is supported with ball bearing, which allows for the movement of the platen during loading.

For using it as a biaxial platen, the figure 3.2 (a) is referred that shows the possible stresses that act on a roof when an entry is created in the coal seam. " $\sigma_{h 1}$ " \& " $\sigma_{h 2}$ " are the in - situ principal horizontal stresses and "V" is the overburden stress. The case where, $\sigma_{h 1}=\sigma_{h 2}$, was 
tried to replicate inside the platen as shown in figure 3.2 (b). "P" is the load provided by the uniaxial compression testing machine from the bottom moving platen, " $R$ " is the reactionary force applied by the top fixed platen. These force are split by the biaxial platens to apply the stress component " $N$ " acting normal to the laminations. Due to the symmetry of the specimen, the forces will distribute equally on the specimen.

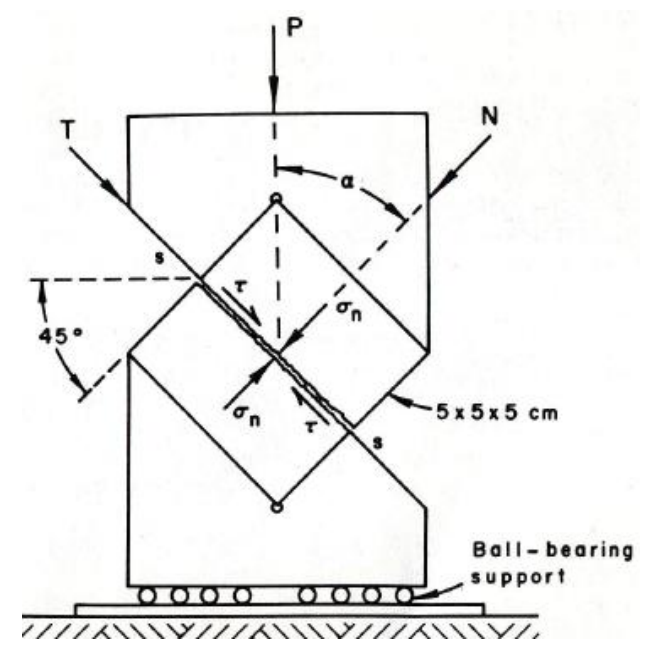

(a)

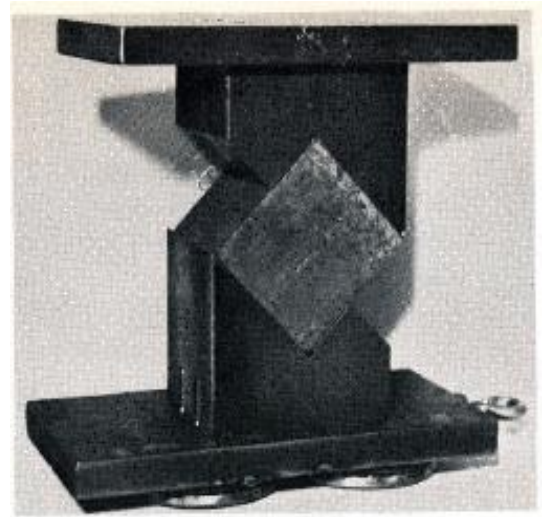

(b)

Figure 3.1(a) free body diagram of the device indicating the forces acting on the specimen (b) the shear device with a rock specimen (after Jumkis and Jumkis, 1975)

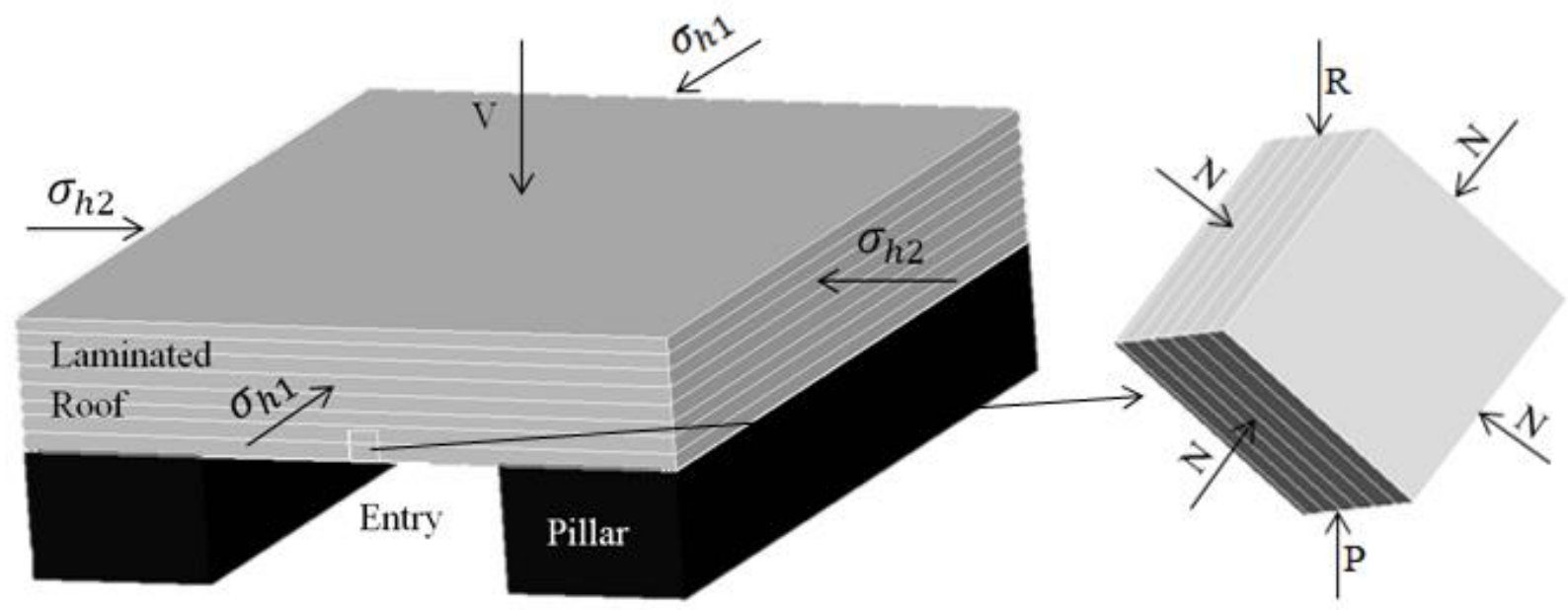

(a)

(b)

Figure 3.2 (a) Stress acting on the roof of an entry (b) Stress distribution on specimen inside UCS testing machine 
The platen was designed using mild hardened steel. The platen was 4.96 inches in length and 2.2 inches in thickness. The inside sections of the platens, "g" and "h," are 2.0 inches and "e" and "f" are 1.8 inches in length. The remaining 0.2 inches on the "e" and " $\mathrm{f}$ " sections allowed movement of the platen. The inside of the platens were grounded to remove any protrusion that will create local stress concentrations. The friction between the rock and platen was ignored and a corrugated fiberboard was used at specimen platen interface for uniform distribution of load on the specimen (figure 3.4).

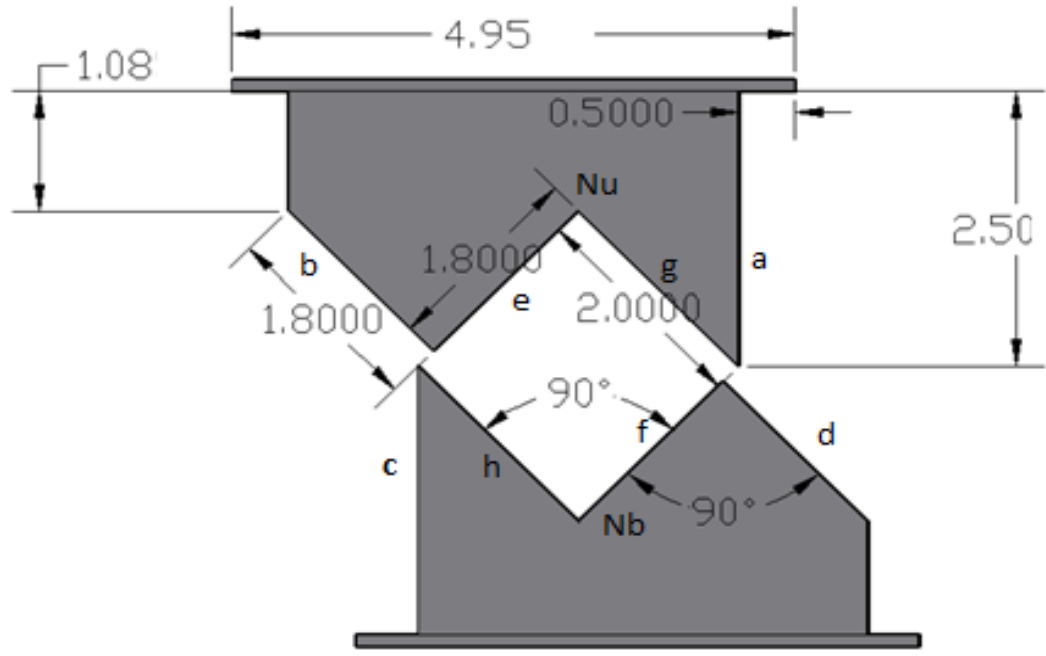

Front

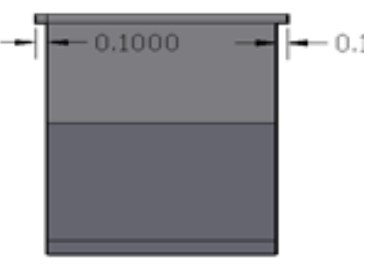

Figure 3.3 CAD drawing of the biaxial platen showing the exact dimensions of the platen

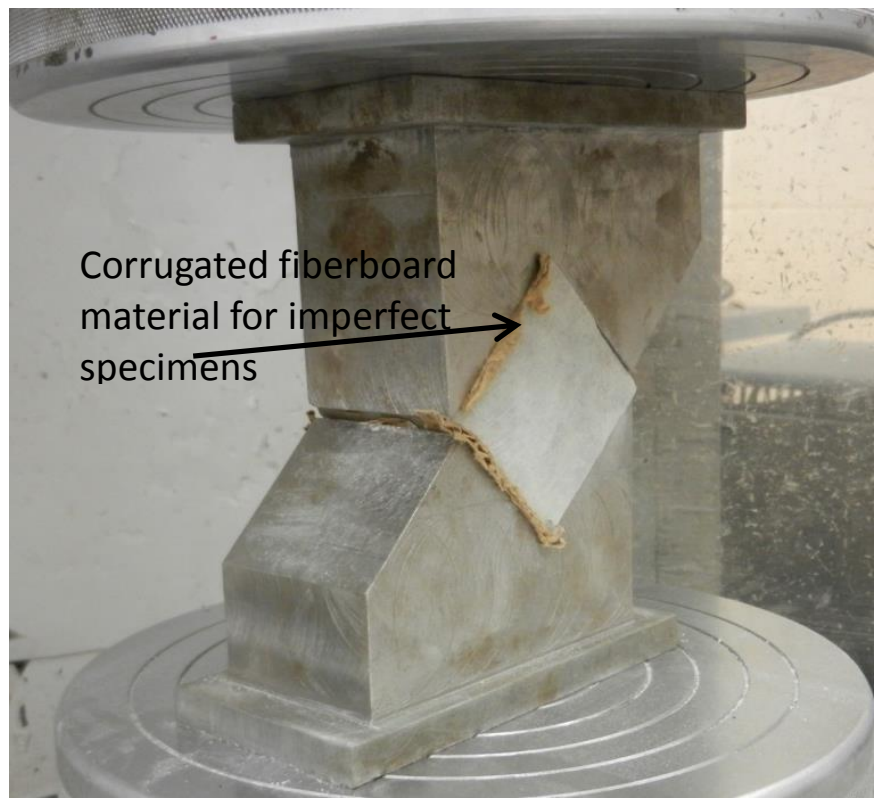

Figure 3.4 Fiberboard material was used for uniform distribution of load on an imperfect specimen 


\subsection{Modification of Biaxial for Triaxial Compression Test}

This approach was designed after initial experiments showed the movement of the unconfined zones of the rock. The objective of this test was to observe and analyze the effect of confinement on the movement of the rock and failure of the specimen. For confining the exposed zones of the rock, the initial thought was to use hydraulic jacks with metal plates that will restrict the movement of the rock. However, limited space and the constraints of further fabrication prevented the use of the jacks. A simpler option was then adopted by using a c-clamp (Figure 3.5) with metal plates. Applying a confinement by means of a c-clamp and metal plates created a pseudo triaxial condition. Table 3.1 describes the mechanical properties of the c-clamp. Figure 3.5 shows a CAD figure with complete set-up, which is followed by the actual test set-up in Figure 3.6.

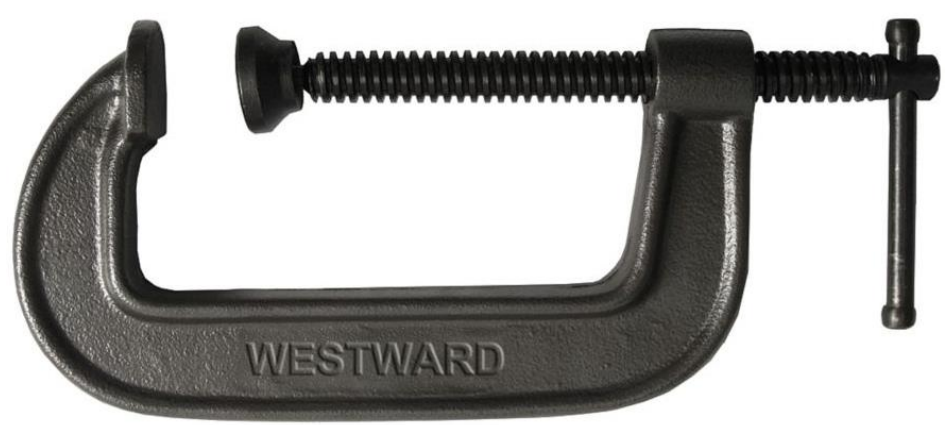

Figure 3.5 The ultra-force steel clamp (Source: www.grainger.com)

Table 3.1 Specifications of c-clamp (Source: www.grainger.com)

\begin{tabular}{|l|l|}
\hline Size (in.) & $7-1 / 4$ \\
\hline Throat Depth (in.) & $3-7 / 8$ \\
\hline Min. Proof Test (lb.) & 12500 \\
\hline Load Capacity (lb.) & 12,500 \\
\hline Clamp Type & Drop-Forged \\
\hline Body Material & Ultra-Force Steel \\
\hline
\end{tabular}




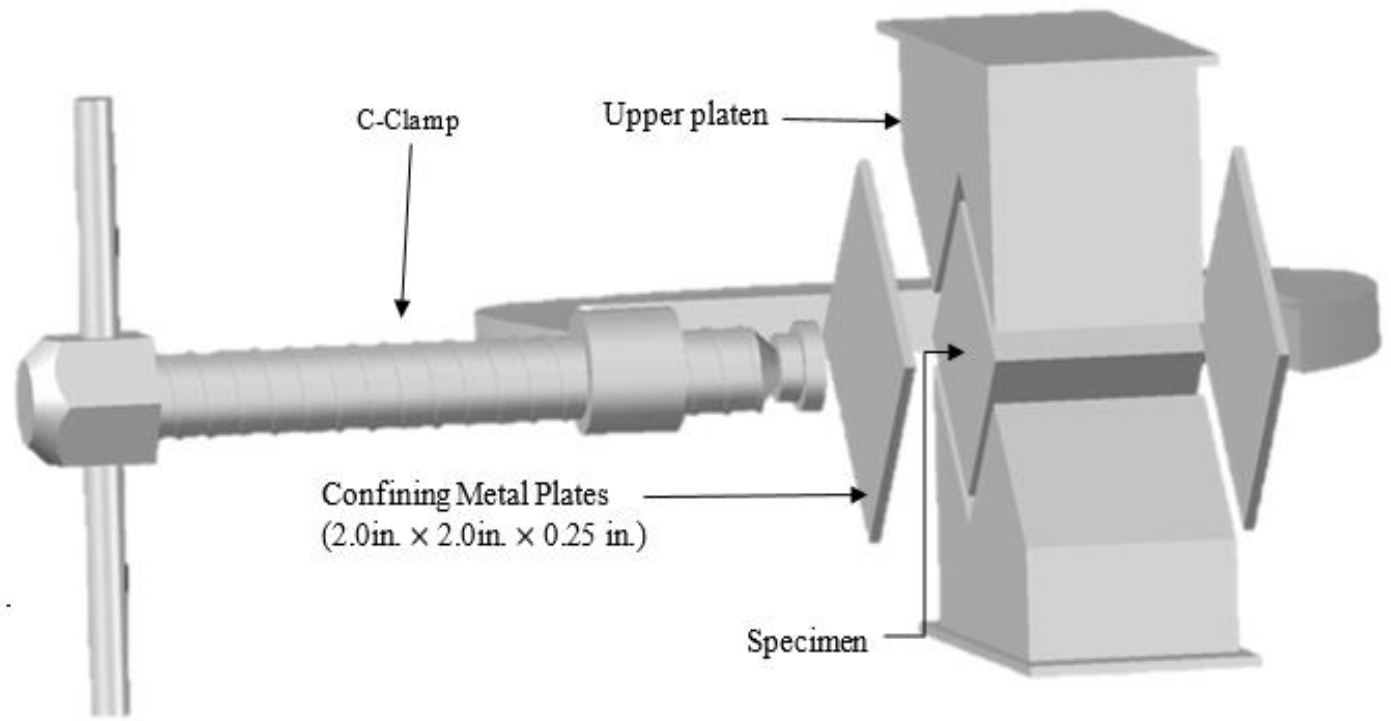

Figure 3.6 Schematic view of experimental set-up with confinement

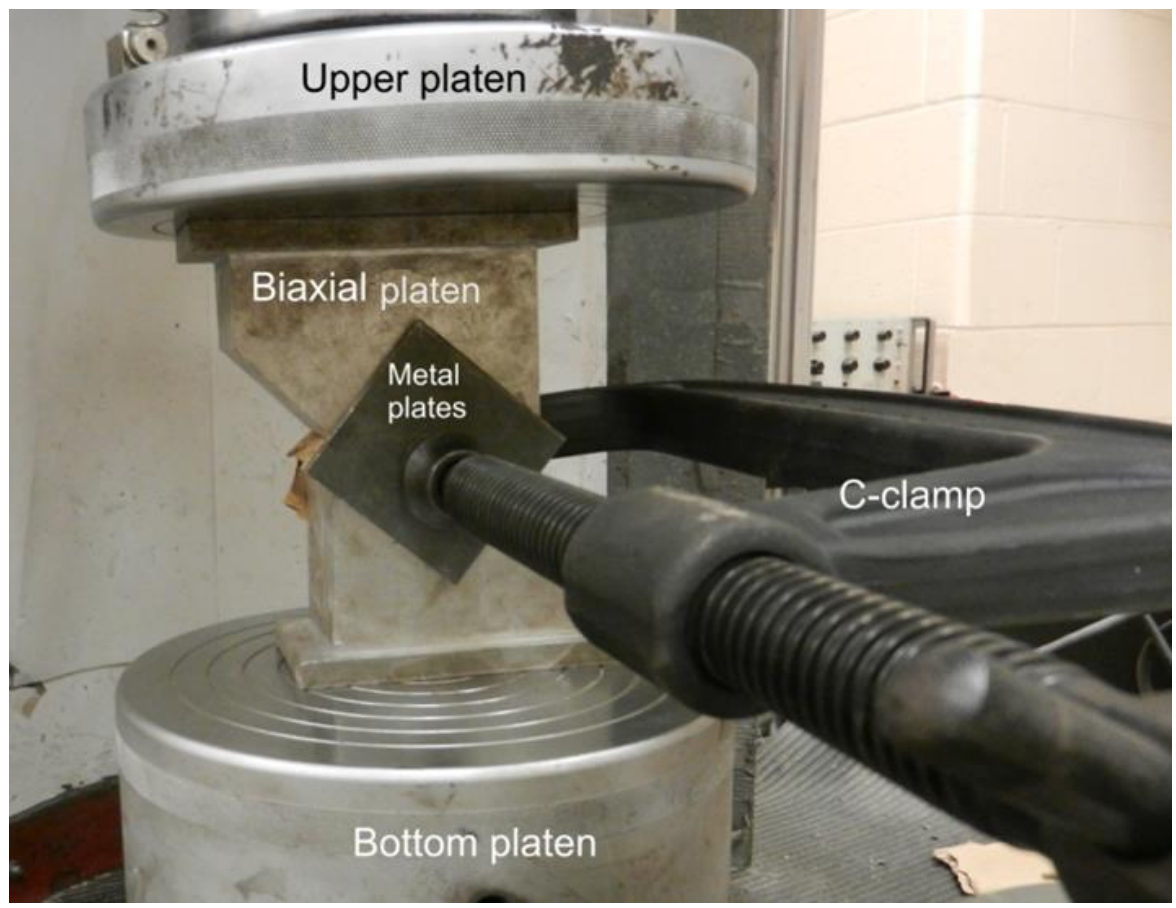

Figure 3.7 Test set-up with biaxial platens and the c-clamp inside the test frame 


\subsection{Uniaxial Compression Testing Machine}

The specimens were tested in a servo-hydraulic compression-testing machine (Material Test System). It is a single-channel type (i.e., one hydraulic actuator and one servo-controller) closed loop system (figure 3.7). A closed loop system consists of a series of interacting elements, wherein the information is transmitted from one unit to another without the loss of signal in between. Load is applied on the specimen using a hydraulic actuator, which produces an accurate and desired force or displacement by operating under precision servo valve control (Figure 3.8). A linear variable differential transformer (LVDT) mounted internally, measures the displacement of the actuator piston rod or the vertical stroke of the hydraulic ram. Hence, it is also used to measure the axial deformation of the specimen.

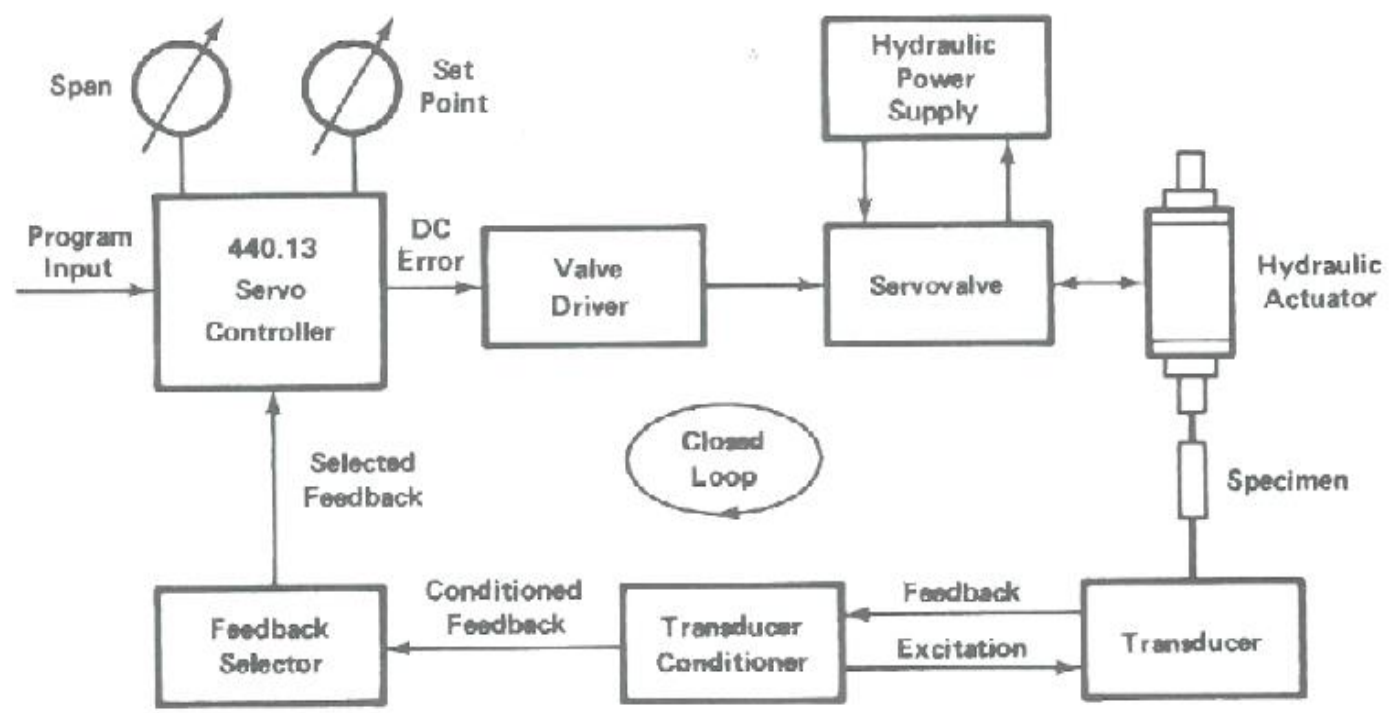

Figure 3.8 Block Diagram of MTS uniaxial compression test system (MTS reference manual, 1990) 


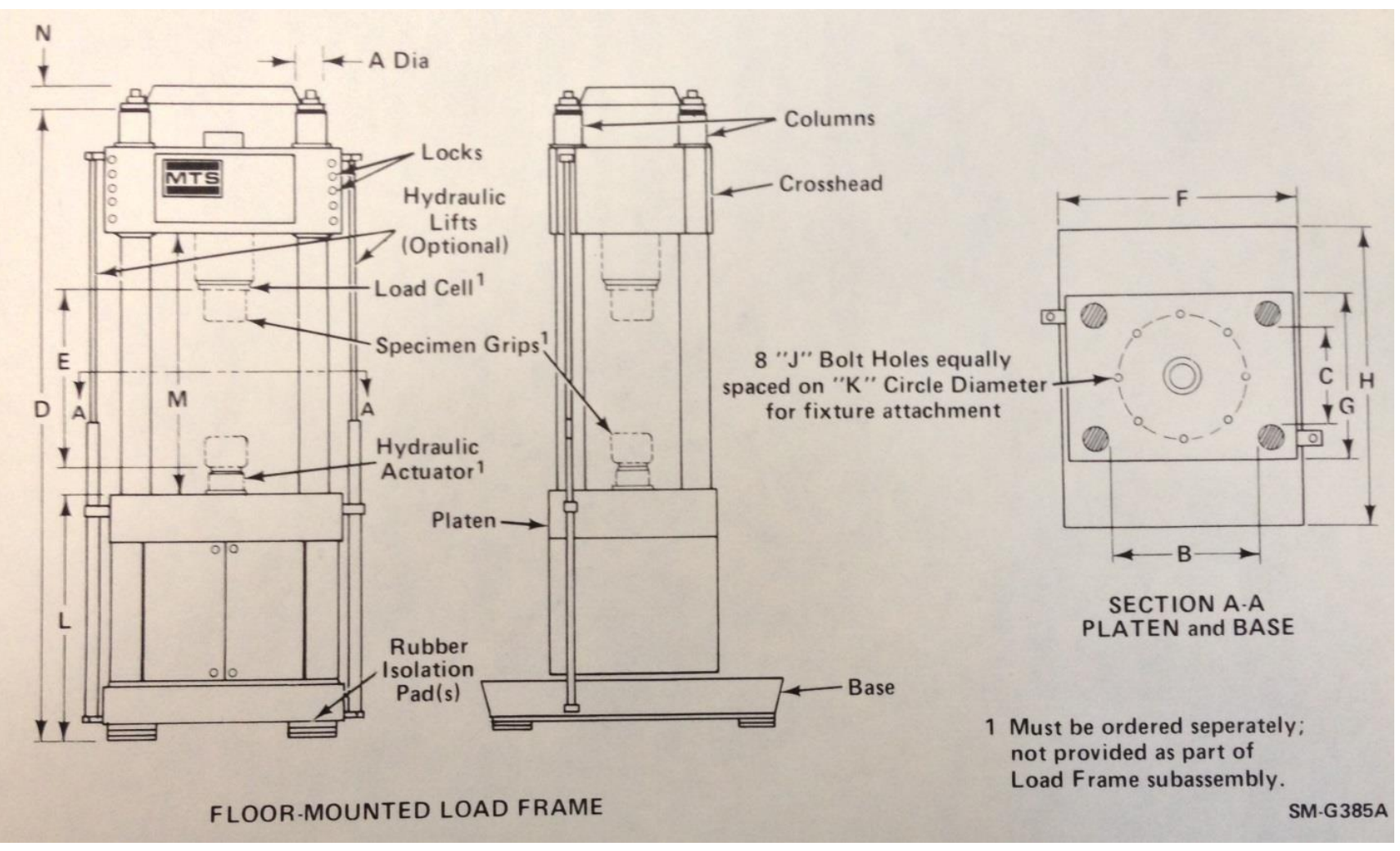

Figure 3.9 Schematic view of the MTS machine (MTS reference manual, 1990)

\subsection{Specimen Preparation}

One of the most arduous tasks in this project was to collect large chunk or boulders of immediate roof of shale formation. In order to obtain a sufficient number of specimens, it was necessary to acquire large boulders from which similar sized specimens could be prepared. However, it was impossible to collect large chunks, and the small samples of rock chunks that were collected from mines could only provide one or two specimens (Figure 3.10(a,b)). Irregularly sized shale rock chunks from the immediate roof were collected from different cutter roof prone mines in West Virginia and Pennsylvania. Rock samples included dark, laminated, and massive shale. From the Illinois basin, 3.0-inch cylindrical specimens were cut and ground to 2.0-inch cubic specimens (Figure 3.10(c)).

The irregular shale samples were cut into 2.0-inch cubic specimen using a machineoperated rock saw with a circular cutting blade. Flattening of specimen surfaces was performed using a combination of a handheld grinding machine and sandpaper. Usage of water for cutting 
and grinding was avoided to prevent flaking and weakening of the shale. However, some specimens were extremely weak and did not withstand the cutting and grinding process.

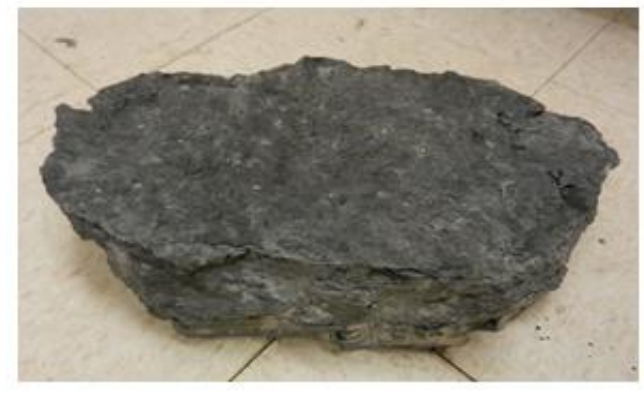

(a)

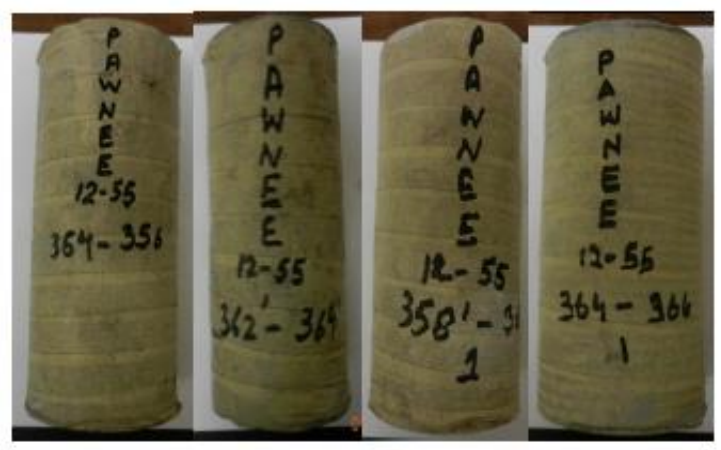

(c)

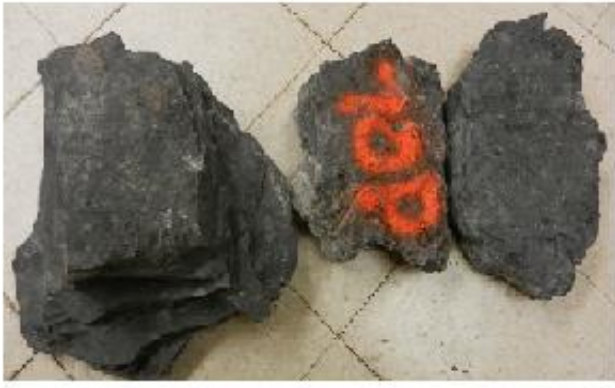

(b)

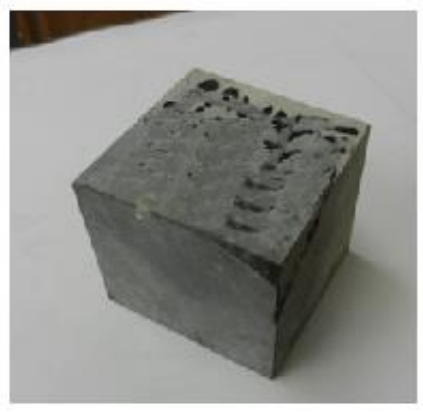

(d)

Figure 3.10 Finished specimen (d) prepared from rock chunks (a, b) and cylindrical specimens (c)

Twenty-three specimens were prepared for the current experimental work. In Table 3.2, the total number of specimens is provided along with rock type and loading condition. It was concluded that the small number of specimens may influence the outcome. Therefore, each test was meticulously documented for capturing every possible piece of information. For the current tests, there were a minimum of four specimens for each rock type, which is sufficient to provide reasonable quantitative and qualitative behavior about the specimens. 
Table 3.2 Description of the specimen with the type of loading condition and number of specimens tested

\begin{tabular}{|c|c|c|}
\hline Loading Condition & Type of Rock & $\begin{array}{c}\text { Number of } \\
\text { Specimen }\end{array}$ \\
\hline Biaxial compressive & Black Shale & 4 \\
\hline & $\begin{array}{c}\text { Laminated } \\
\text { Shale }\end{array}$ & 11 \\
\hline $\begin{array}{c}\text { Triaxial } \\
\text { compressive }\end{array}$ & $\begin{array}{c}\text { Laminated } \\
\text { Shale }\end{array}$ & 4 \\
\hline
\end{tabular}

Each specimen was assigned a tracking name, indicating the name of the seam, and the sample number. Table 4.1 provides the detail name and the number of the specimen, which will be used in results and discussion chapter.

\subsection{Test Procedure}

In the uniaxial and triaxial tests, the platen is moved with hydraulic ram that will compress the specimen to its failure point. The movement of the platen is either by force control or by stroke control. The uniaxial compressive tests and triaxial tests are regularly performed at 100 psi per second. In stroke control mode, the tests are performed at 0.0001 inch per second. These rates ensure any differences in results due to time-dependency and high strain-rate loading is minimized. For the current tests, stroke control mode was adopted for loading the specimen.

The MTS (Material Testing System) consists of a data acquisition system and a standalone software that is used for designing and running a suite of tests. The MPT (Multi-purpose Test software) allows the user to program various load paths and constraints for completion of the test. The specimen with the platen was assembled before being placed on the machine's platen. For ensuring that the specimens have full contact with the platen, corrugated fiberboard was placed between the platen and the specimen. The entire set-up was then placed on the machine's platen and a small load of 100lbs was applied to raise the platen and ensure proper contact between the platens of the machine and biaxial platen. The MPT run command was invoked to move the platen and apply load on the device. As the test progressed, failure in the 
specimen was carefully recorded. The test was terminated when the platens exceeded a displacement greater than 0.1 inch. On the completion of the test, the specimen failure was analyzed and photographed to capture the post-test state of the specimen. The tests were also recorded using a digital camera for analyzing the failure process. The force versus displacement data recorded by the MPT software was then further analyzed. Approximate peak stress applied on the specimen was calculated using equations 3.1 and 3.2

$$
\begin{array}{cl}
\mathrm{N}=\mathrm{P} \cos 45^{\circ} & \text { Equation (3.1) } \\
\text { Approximate Peak stress = N/A } & \text { Equation (3.2) }
\end{array}
$$

Where:

$$
\begin{aligned}
& \mathrm{N}=\text { the normal load on the specimen } \\
& \mathrm{P}=\text { the load applied by the load frame } \\
& \mathrm{A}=\text { approximate area of the specimen }
\end{aligned}
$$

\subsection{Test Limitations}

There are few limitations and assumptions of the biaxial and triaxial tests as listed below:

1. Effect of friction between the platens of the load frame and the biaxial platens was not investigated.

2. Effect of friction between biaxial platens and specimen was not investigated.

3. No strain measurement was performed on the specimen.

4. The c-clamps are designed to apply a maximum load of 12,500 lbs. (Table 3.1) along the screws when they are completely tightened. This load was used to press the metal plates on to the specimens that provided the confinement. The maximum confinement achieved during the triaxial tests was not recorded. 


\section{Chapter 4}

\section{Results and Discussion}

In this chapter, the results from both the biaxial and triaxial test results are presented followed by discussion. Nineteen specimens were tested using the biaxial platen; the specimens included eleven laminated shale, four black shale, and four limestone. Four laminated shale specimens were also tested under confined conditions. Each specimen result is explicitly analyzed and discussed. The effect of the biaxial stress on shale rock showed unique failure. Some findings support the field observations while others need to be extensively researched.

In each test, the specimens were referenced using site-specific name. For example, $(\mathrm{P})$ indicates the specimen was prepared from the rock obtained from Pittsburgh seam, (I) indicates Illinois No. 6 seam, and G represents the No. 2 Gas seam.

Table 4.1 Specimen information

\begin{tabular}{|c|c|c|}
\hline & Specimen Name & Rock Type \\
\hline & Biaxial Test & \\
\hline 1 & $(\mathrm{P} 1)$ & Black Shale \\
\hline 2 & $(\mathrm{P} 2)$ & Black Shale \\
\hline 3 & $(\mathrm{P} 3)$ & Black Shale \\
\hline 4 & $(\mathrm{P} 4)$ & Black Shale \\
\hline & & Laminated Shale \\
\hline 1 & $(\mathrm{I} 1)$ & Laminated Shale \\
\hline 2 & $(\mathrm{I} 2)$ & Laminated Shale \\
\hline 3 & $(\mathrm{I} 3)$ & Laminated Shale \\
\hline 4 & $(\mathrm{I} 4)$ & Laminated Shale \\
\hline 5 & $(\mathrm{G} 1)$ & Laminated Shale \\
\hline 6 & $(\mathrm{G} 2)$ & Laminated Shale \\
\hline 7 & $(\mathrm{G} 3)$ & Laminated Shale \\
\hline 8 & $(\mathrm{G} 4)$ & Laminated Shale \\
\hline 9 & $(\mathrm{G} 5)$ & Laminated Shale \\
\hline 10 & $(\mathrm{G} 6)$ & Laminated Shale \\
\hline 11 & $(\mathrm{G} 7)$ & \\
\hline & & \\
\hline
\end{tabular}




\begin{tabular}{|c|c|c|}
\hline 1 & (I5) & Limestone \\
\hline 2 & (I6) & Limestone \\
\hline 3 & (I7) & Limestone \\
\hline 4 & (I8) & Limestone \\
\hline & Confined Test & \\
\hline 1 & (P5) & Laminated Shale \\
\hline 2 & (P6) & Laminated Shale \\
\hline 3 & (P7) & Laminated Shale \\
\hline 4 & (P8) & Laminated Shale \\
\hline
\end{tabular}

\subsection{Biaxial Tests}

\subsubsection{Effect of biaxial load on black shale specimens}

The first series of four tests were performed on black shale specimens from the Pittsburgh seam. The loading platens were programmed to move under stroke control that allowed for close observation of the failure of the specimen. Failure in the specimen included separation of laminated layers, crack development, and propagation.

The post-test state of the first specimen in this group is pictured in Figure 4.1(a), which is accompanied by the plot of the load versus displacement (Figure 4.1(b)). The failed specimen showed sets of localized failure developing close to the exposed surfaces that moved inwards within the specimen. Superficial cracks were visible; however, no major fracture was observed in the rest of the specimen. In the second, the specimen failed along the unconfined faces, and chunks of broken rock were disassociated from the specimen (Figure 4.1(c)). The specimen reached a maximum load of 45,000 lbs., and the test was terminated to prevent any contact between the platens (Figure 4.1 (d)).

In the third test (Figure 4.1 (f)), the rock specimen reached a maximum load of 55,000 lbs., beyond which the material showed residual strength. On analyzing the specimen, it was observed that the failure progressively moved inwards (Figure 4.1(e)). In the fourth test, the specimen reached a maximum load of 35,000 lbs. (Figure 4.1(h)), beyond which it plateaued and plastic-type showed residual strength. On close observation of the picture (Figure 4.1(g), it is seen that large chunk of the material failed along the unconfined zone. 


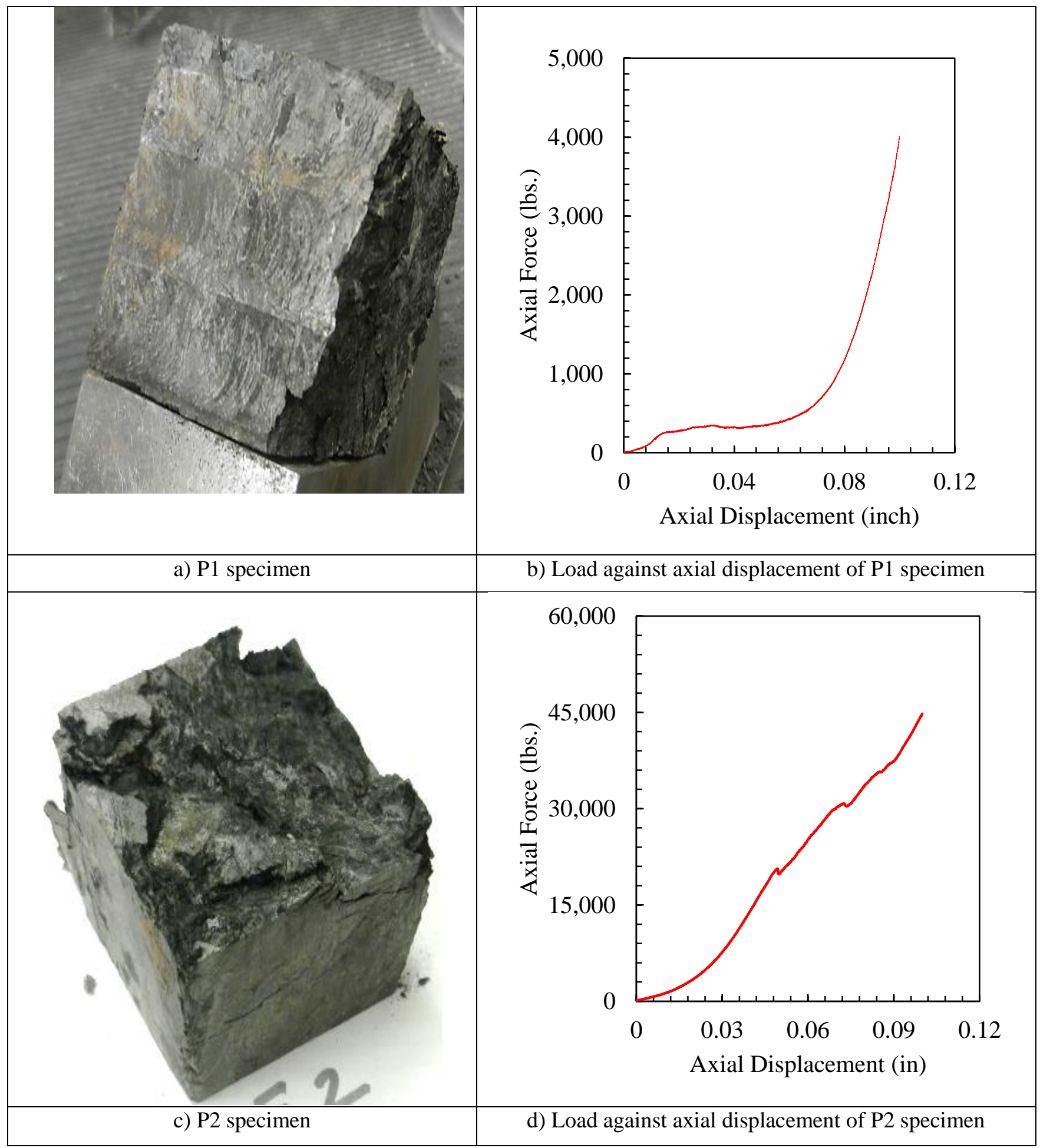




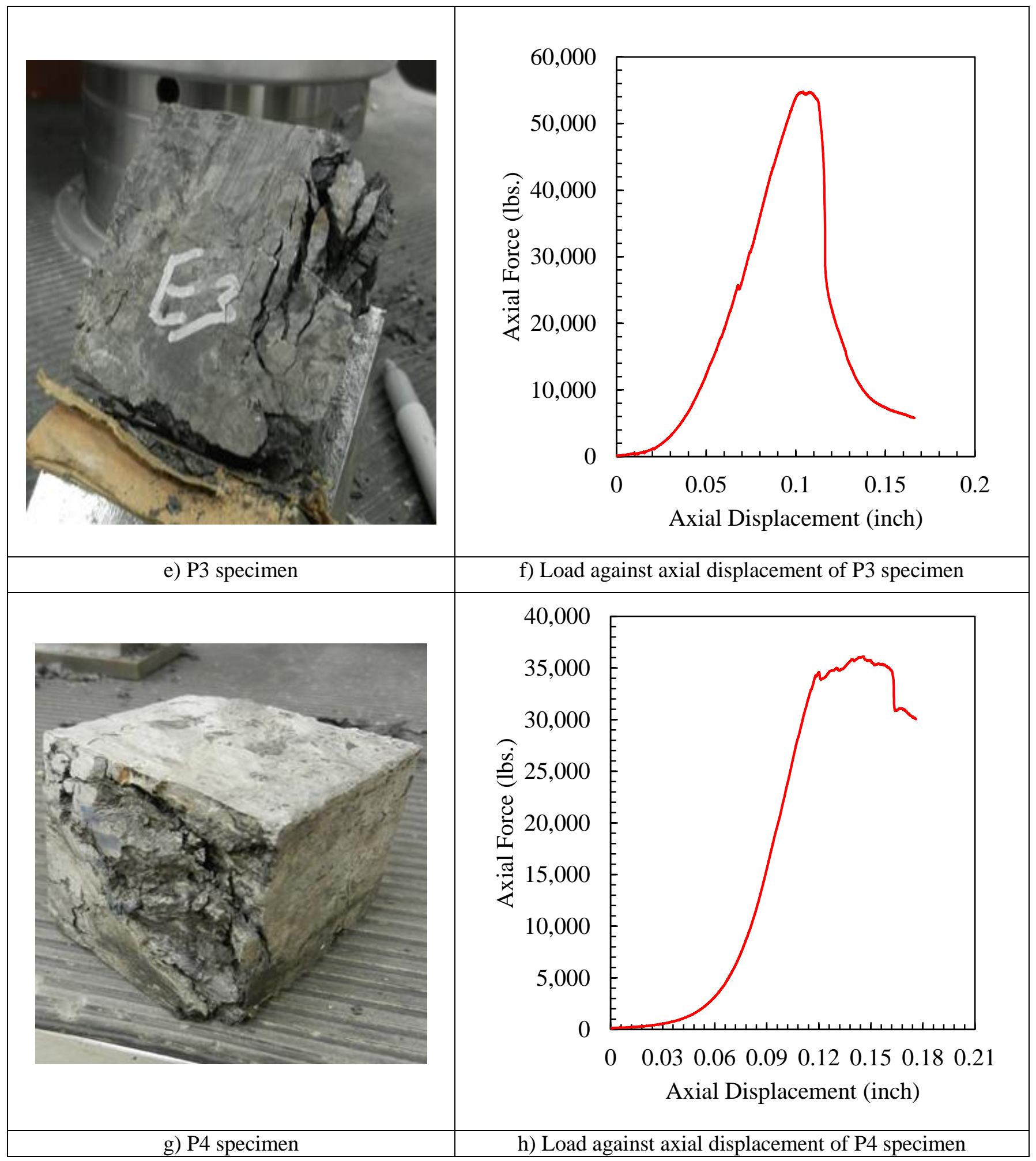

Figure 4.1 Pictures and plots of axial force against displacement of black shale specimens tested in biaxial platens 
The failure and ejection of small chunks in all four tests showed that the material was extremely brittle in nature. Additionally, it showed that there was a progressive failure and load transfer from the unconfined zone to the confined zone. The extreme brittleness and lower strength of the rock may result in failure and inward propagation of the failure zone as observed in cutter failure. However, from the four black shale test specimens it was difficult to generalize this behavior and therefore the test was recorded using a digital camera for capturing the failure more accurately than the post-test pictures. Next, laminated shale specimens were tested using the biaxial platen.

\subsubsection{Effect of biaxial loading on the laminated shale specimen}

These tests were performed on laminated specimens that were collected from mines in Illinois and West Virginia. From the Illinois mine, specimens with distinct laminations were prepared and tested in the biaxial device. For these tests, the orientation of laminations inside the device and the side of the specimens of which snapshots are presented in this discussion are shown in Figure 4.2.

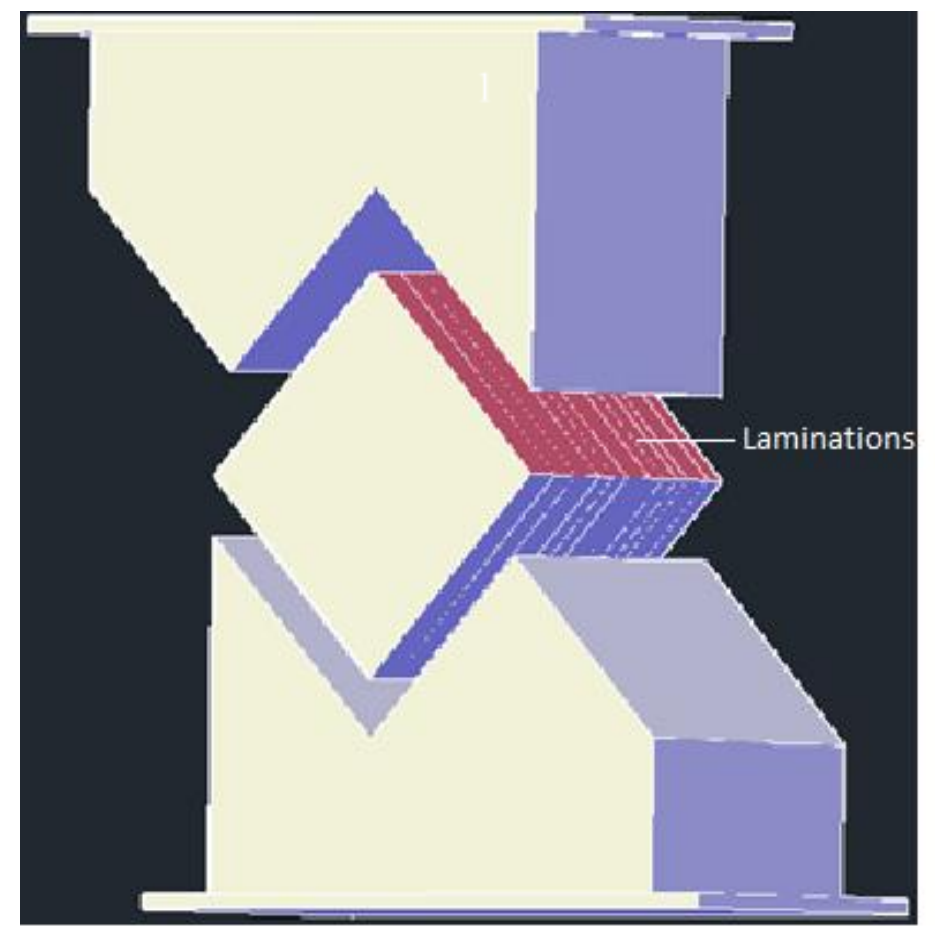

Figure 4.2 The shaded side (magenta colored) of which the snapshots are presented and the orientation of laminations inside the device 
Cutter failure in laminated rock has been extensively researched and analyzed through sophisticated numerical models. Various researchers (Kirapov, 1992, Chen 1999, Gadde and Peng, 2005; Ray, 2009) have consistently treated the laminated rock with a strain-softening material model. The selection of this type of model stems from field observation. In Figure 4.3, the laminated layer is observed to bend towards the entry and fail. Subsequent unsupported regions within the encircled zone fall off, creating a cavity called a cutter. The failure also is observed near the rib, which is not supported. Once the failure is identified as cutter failure, the roof is then supported by standing supports to prevent further progression of the failure. The process of how the high horizontal stress breaks the laminated layer in this manner is not understood properly. It is also not known whether the laminated layers move and then fail, or simply bend and fail.

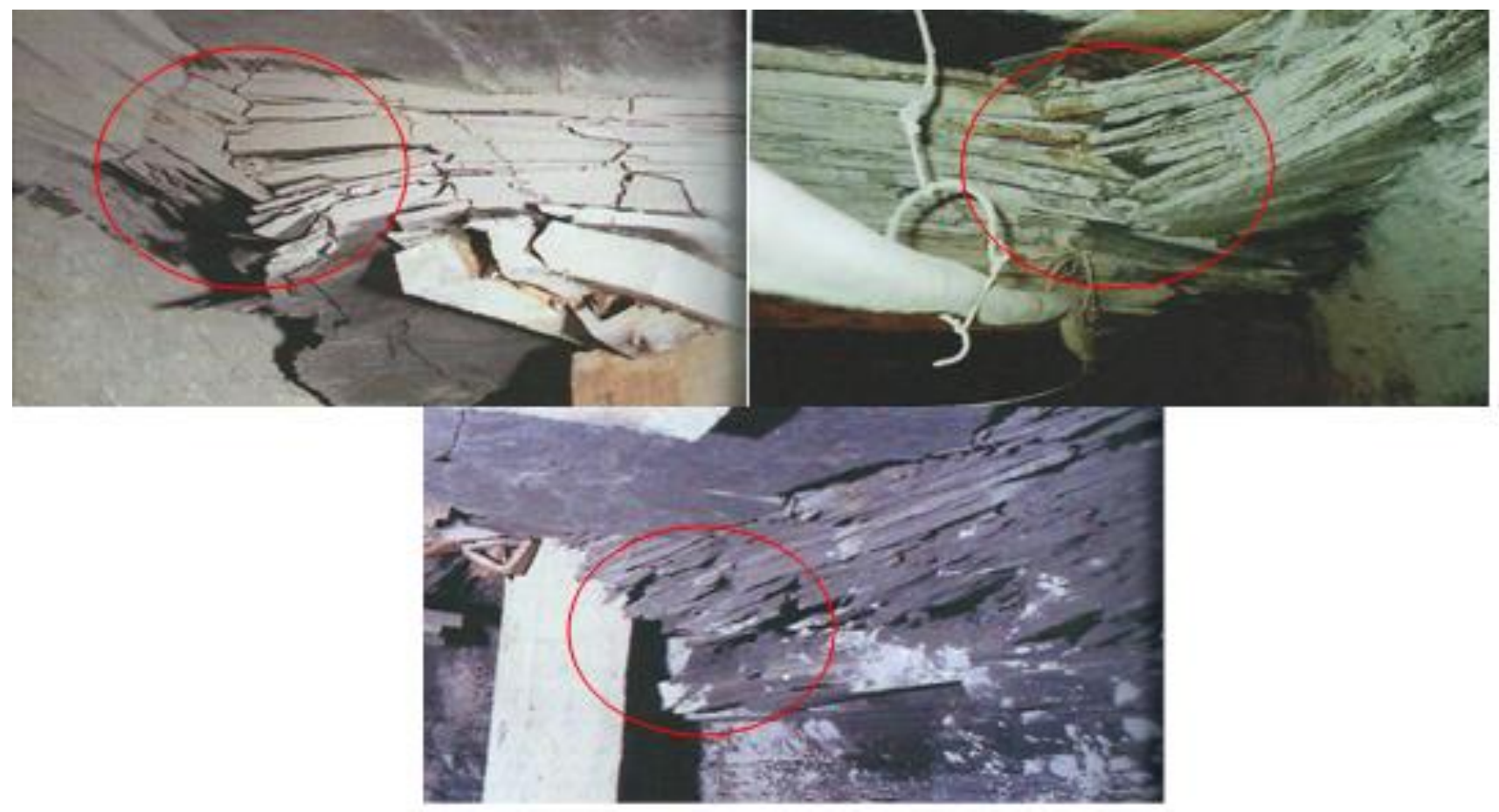

Figure 4.3: Separation of lamination observed at cutter location in a mine entry (Peng, 2007)

Based on in-situ observation, the test was designed to investigate the movement of the laminated layer of the rock and the failure of the specimen. The laminations were clearly visible in all the specimens. In the first specimen, the laminated layers failed in a domino effect when the unconfined zones failed. Figure 4.4(a) shows the separation along the laminations. Additionally, the test was terminated at a load of 6,000 lbs. to observe the failed state (Figure 
4.4(b)). Near the maximum load, multiple peaks were observed that we believe showed that the individual laminated layers failed as they separated. In the second specimen, separation was more clearly observed and the progressive failure of the layers was visible (Figure 4.4(c)). The specimen failed at a maximum load of 12,000 lbs. (Figure 4.4(d)). Towards the unconfined ends, large separation was observed, while at the center of the specimen, crack development was more pronounced. The residual rock showed some residual strength, which showed that each laminated layer provided some remnant strength before complete failure. In the third specimen, failure occurred with the separation of thicker layers of laminations (Figure 4.4(e)). The specimen also showed a relatively high maximum load of 45,000 lbs. (Figure 4.4(f)), which was higher compared to the strength of other specimens. In the fourth specimen test, the specimen failed at a maximum load of 9,000 lbs. (Figure 4.4(h)) with clear separations of the laminations (Figure 4.4(g)).

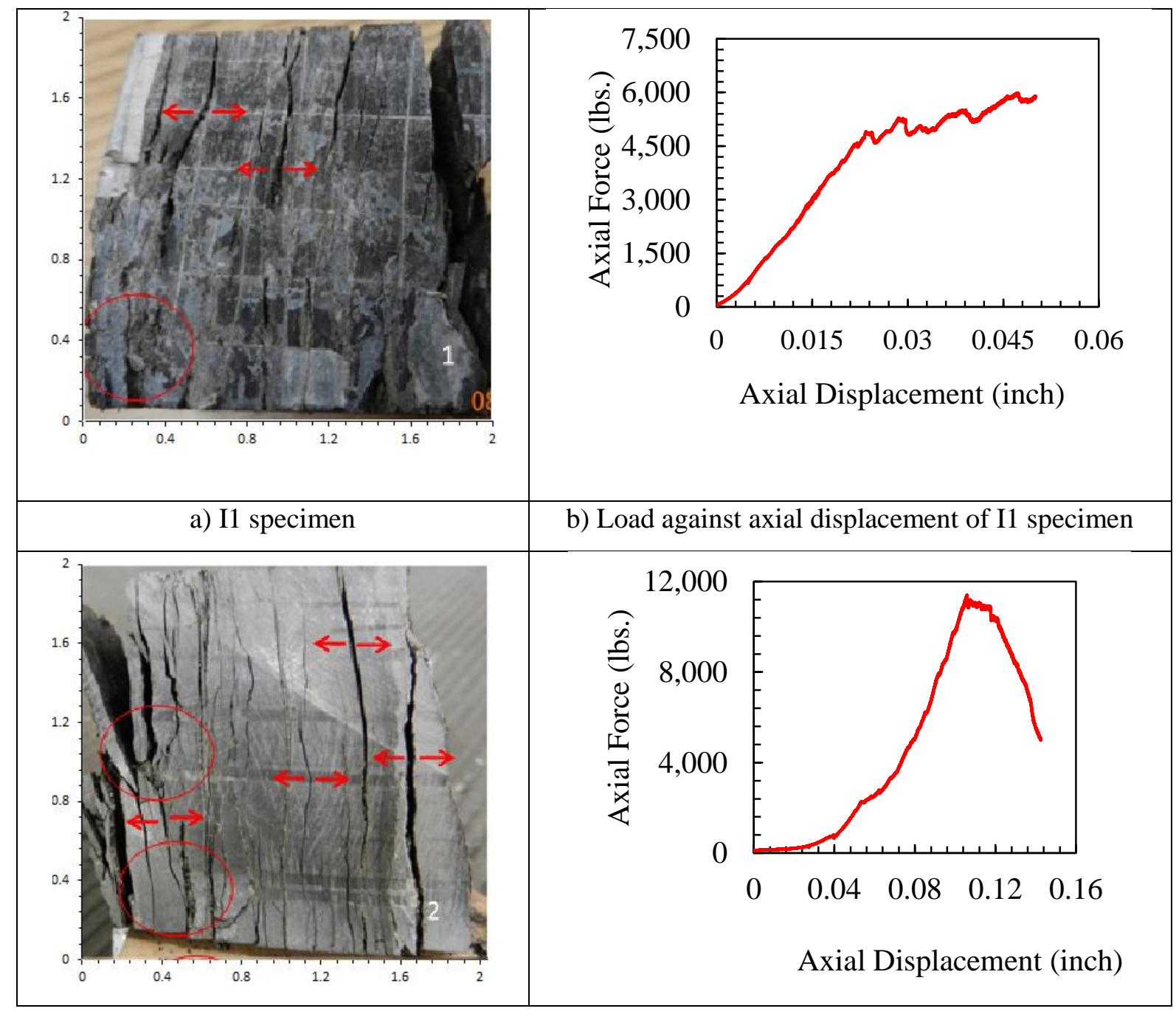




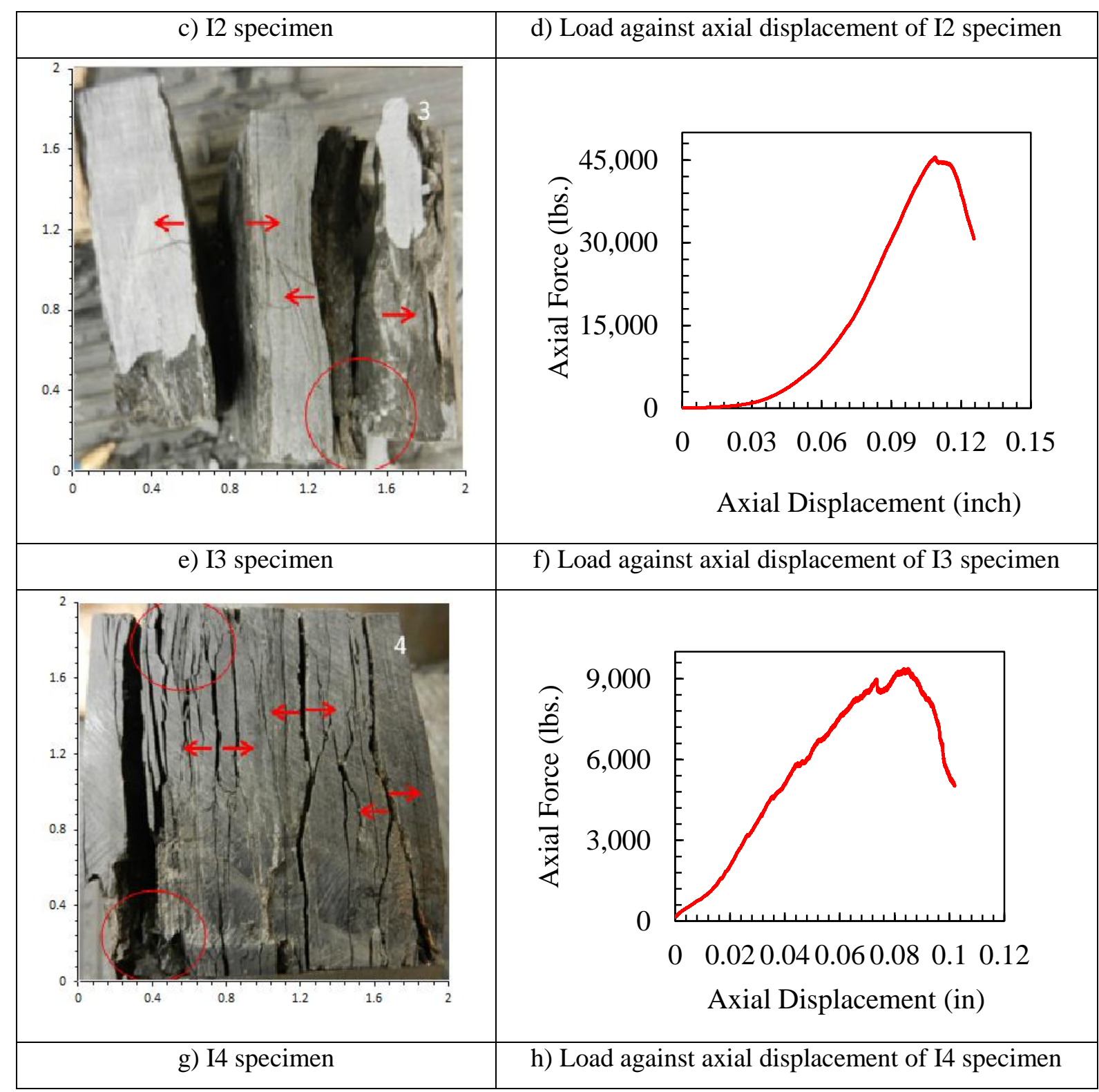

Figure 4.4 Load vs. displacement graph of laminated shale specimens tested in bi-axial compressive loading condition

The observations presented in the previous section raised an immediate question pertaining to the mode of failure in the laminated shale specimens loaded under biaxial compression. The subsequent discussion is about an experimental set-up for determining the mode of failure and subsequent findings.

To determine whether the lamination layers shear against each other, two concentric squares were drawn (Figure 4.5(a)) on one side of the square specimen (figure 4.5(b)) using a permanent marker. Their sides were 1.5 inch and 1 inch respectively. Any distortions in the 
shape of these markings are supposed to provide evidence of shearing. Similarly, one-half of a side of the specimen (Figure 4.6) was spray painted with white enamel paint to highlight the development of fractures after the test. Seven specimens were used for this protocol.

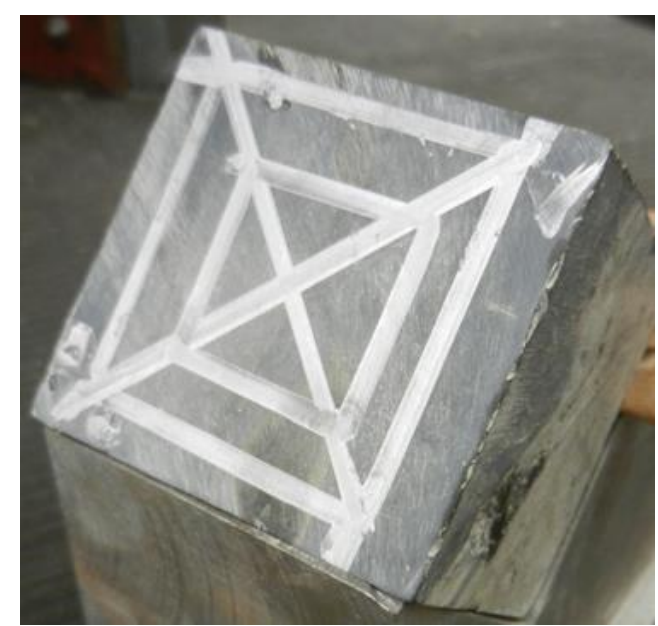

(a)

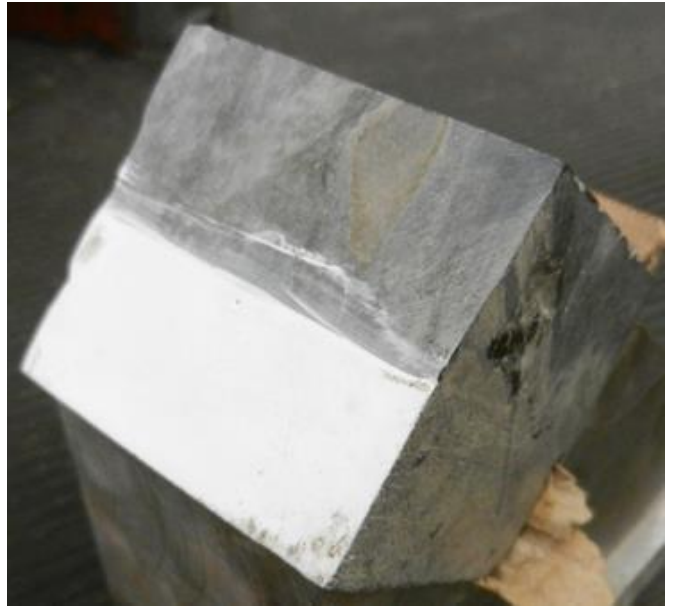

(b)

Figure 4.5 (a) Markings on specimen to determine shearing of lamination under biaxial loading conditions, (b) Spray painted side of the specimen to determine tensile fracturing

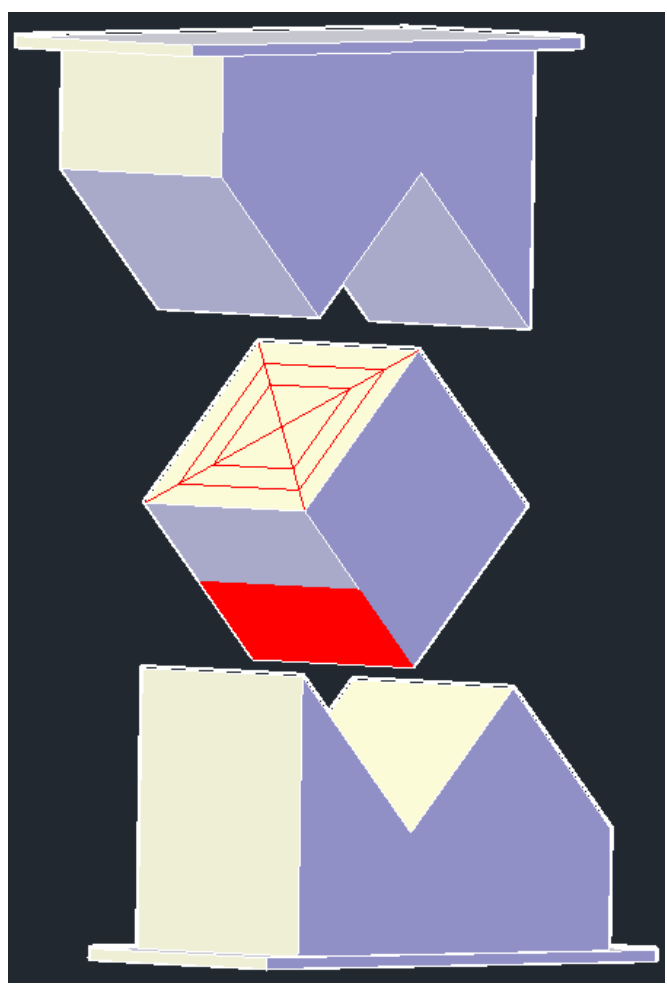

Figure 4.6 Position of failure mode indicators on the specimen with respect to the biaxial platens 
The results of this test strongly suggested that the laminated shale specimens underwent splitting under biaxial compressive loading. This is substantiated by the post-test state of mode indicator as described earlier. There was almost negligible (figure 4.7(a)) distortion of shapes of concentric squares. From Figures 4.7 and 4.8, it was observed in all the specimens that the load was progressively transferred from the outer edge of the unconfined end of the specimen to the inner, relatively intact zone. The inner layers only showed development of cracks that coalesced with each other to form a bigger network of cracks in some specimens. However, shearing of the layers was not observed in the post-failed state. It is possible that at the micromechanical level, shear failure might develop in the specimen, which was not observed in the post-failed state.

Additionally, it was also observed that the specimens showed vertical splitting similar to splitting in the Brazilian tests (Figure 4.9). For verifying such observations, the specimen was painted as mentioned in the earlier sections. A possible explanation is that the laminated layers are poorly connected with each other and therefore form the weakest link. When the load is applied parallel to the lamination, the specimen will expand, which will create tensile stresses in between the laminated layers, resulting in the splitting of the specimen. The outer layer will bend and fail in flexure. The load will then be transferred onto the remaining layers that will also bend and fail. The bending of outer rock layers also causes movement of the layer along the platens. Near the core of the specimen, the layers are in a more confined state and therefore failed when their structural strength was exceeded. For understanding the movement of the unconfined zone, three specimens from this group of tests were recorded and the movement was analyzed. The results are presented in the next section.

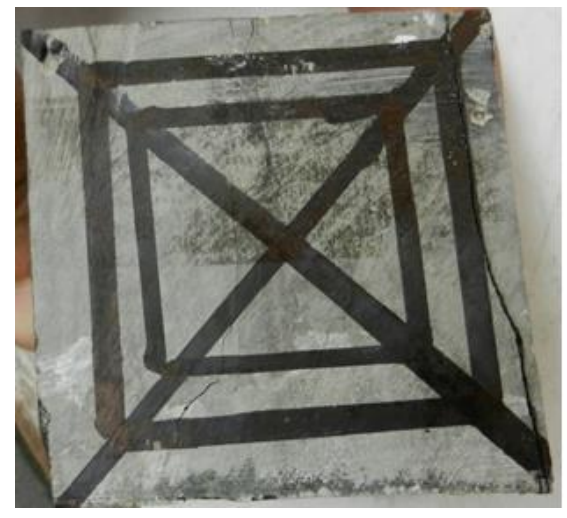

a) Shear movement indicators

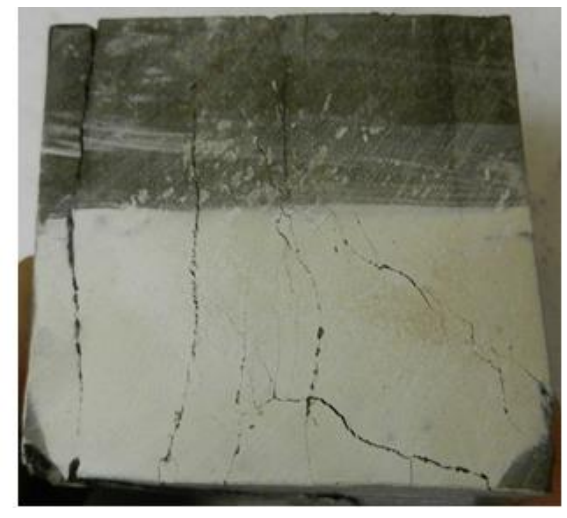

b) Splitting indicator

Figure 4.7 Post-test failure mode indicators on G1 specimen 


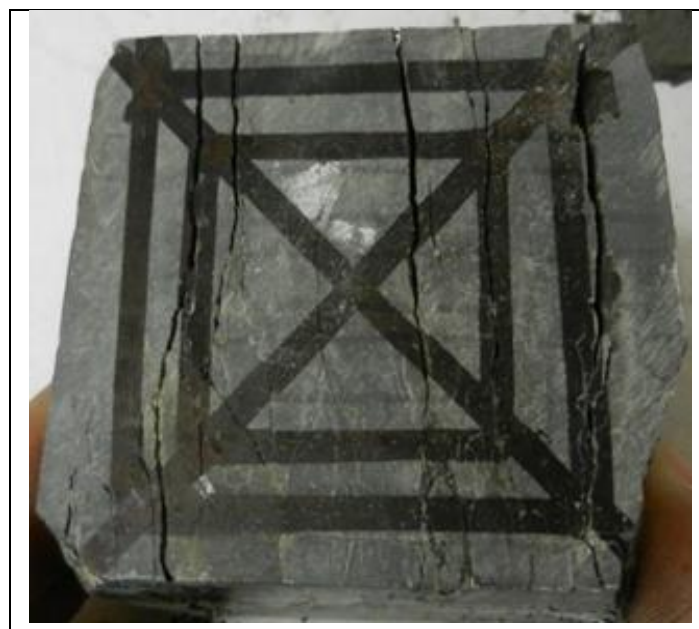

a) G2 specimen

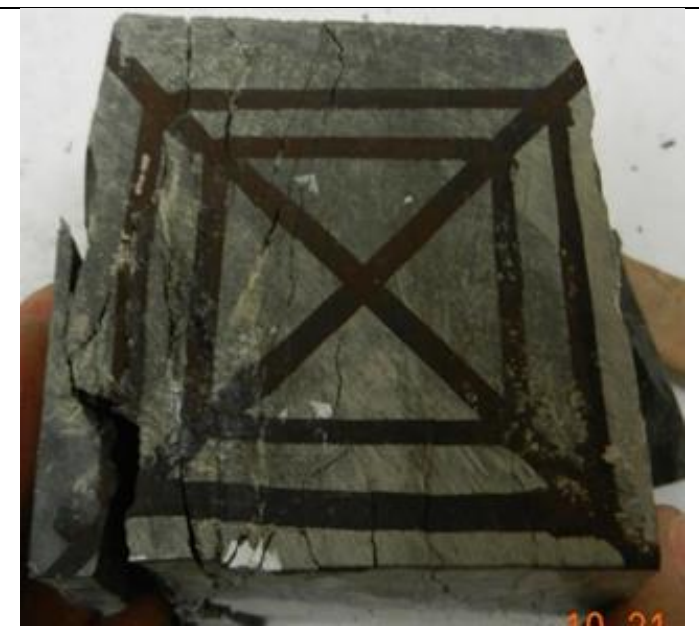

b) G3 specimen
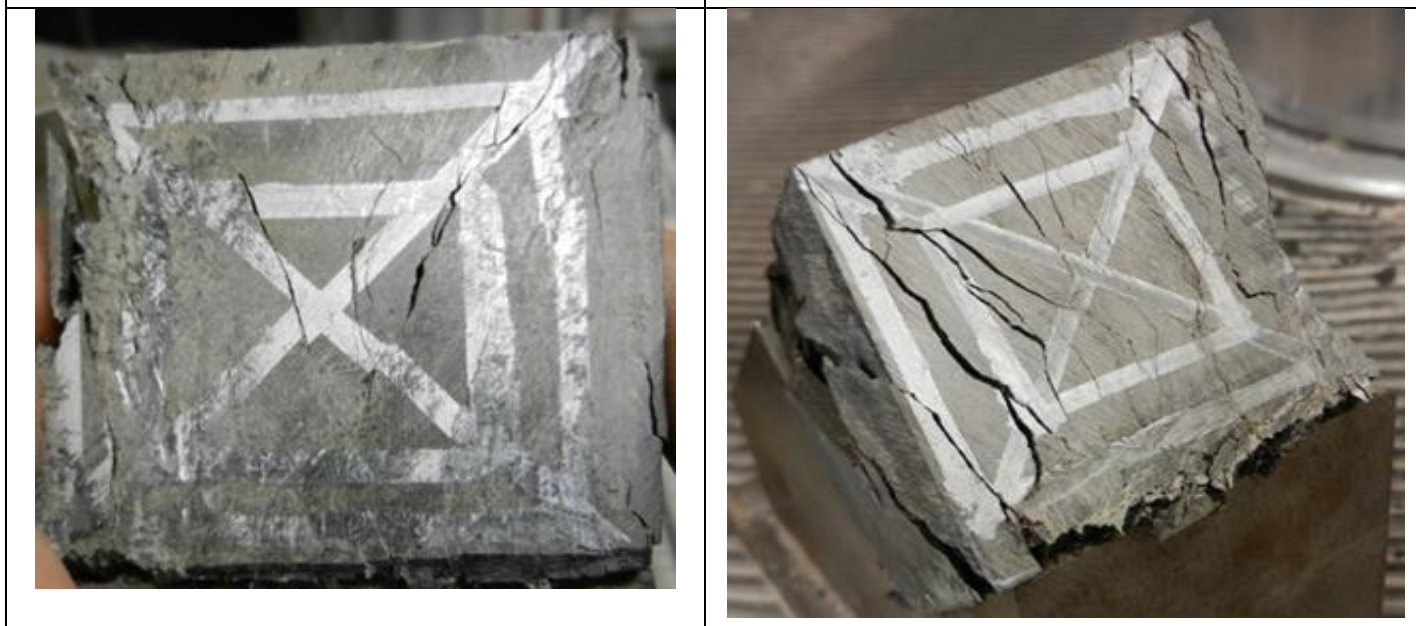

b) G5 specimen

a) G4 specimen

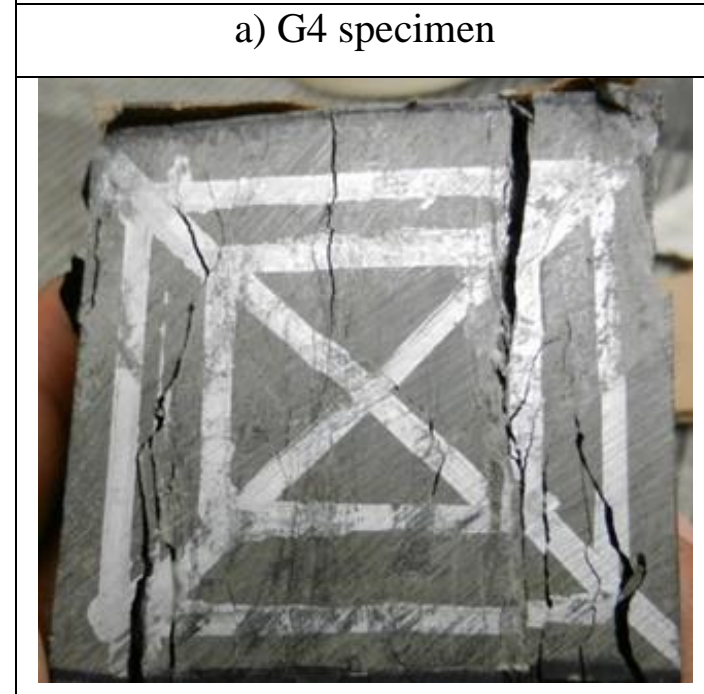

a) G6 specimen

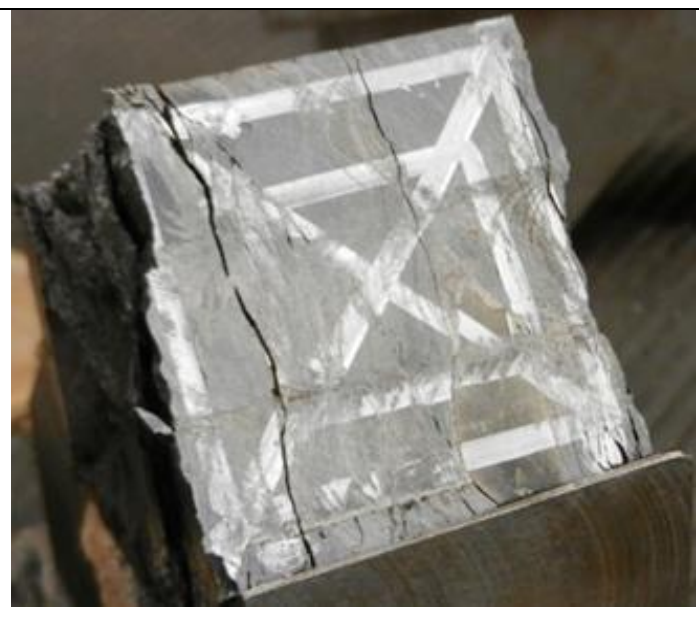

b) G7 specimen

Figure 4.8 Post-test condition of shear movement indicator 


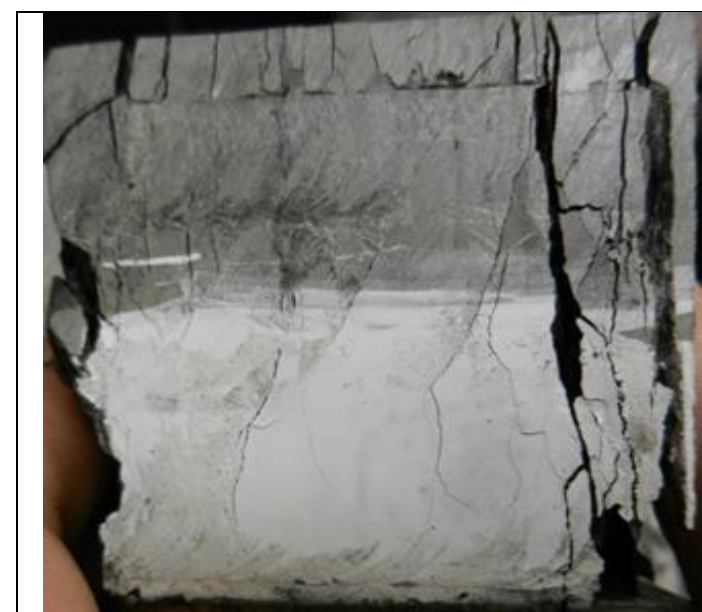

a) G2 specimen

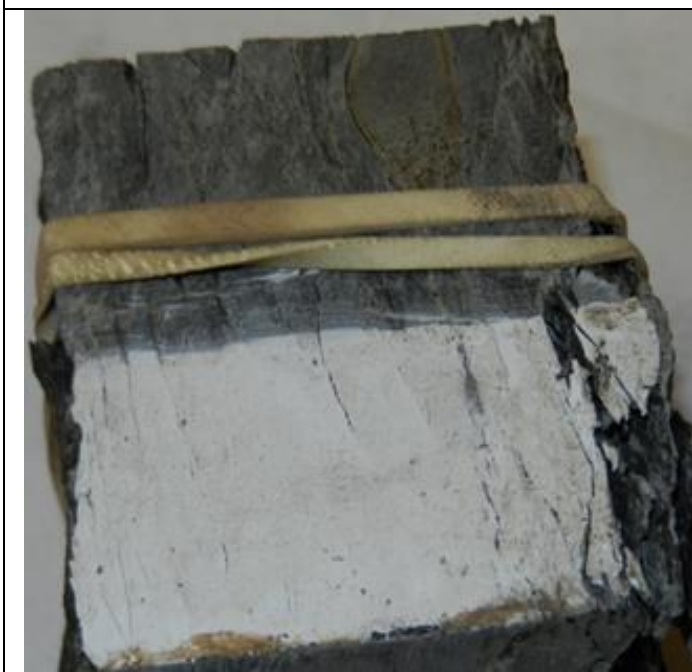

a) G4 specimen

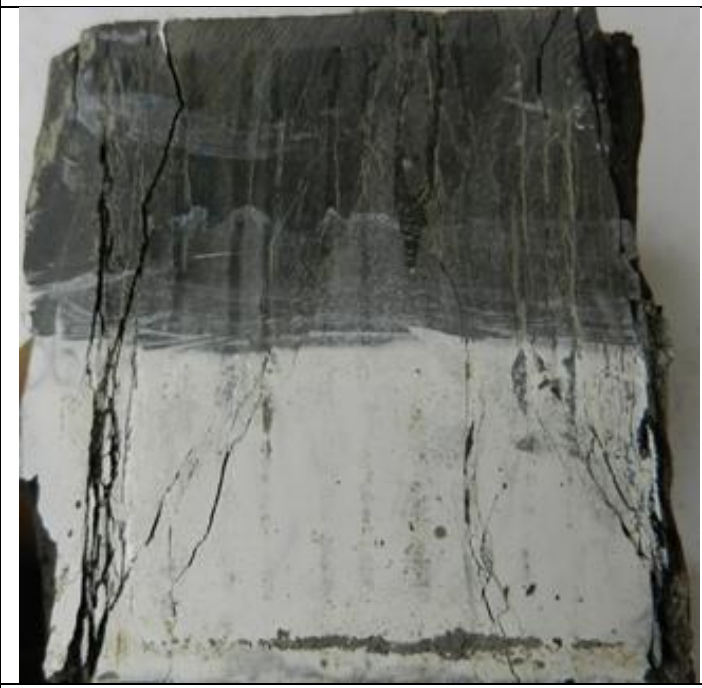

a) G6 specimen

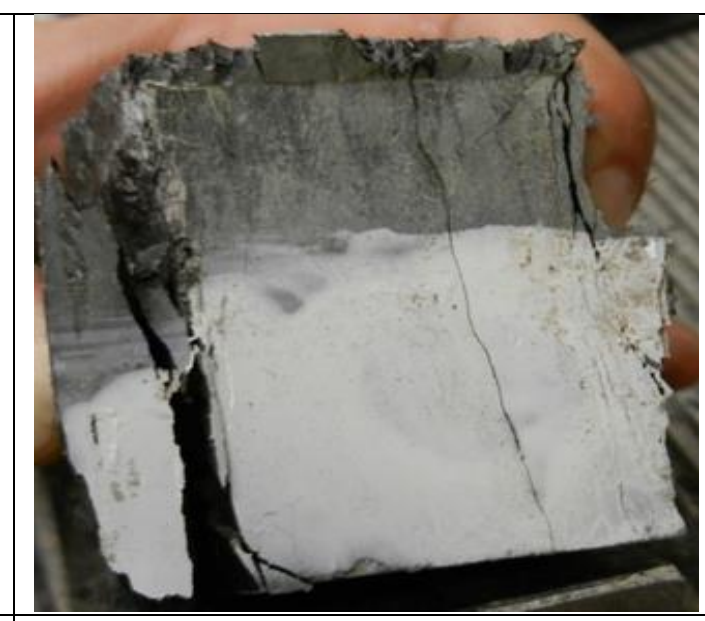

b) G3 specimen

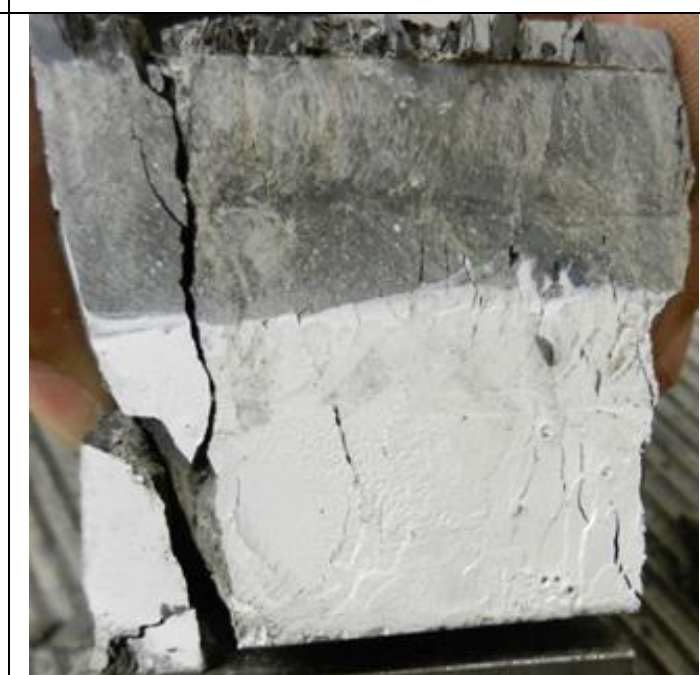

b) G5 specimen

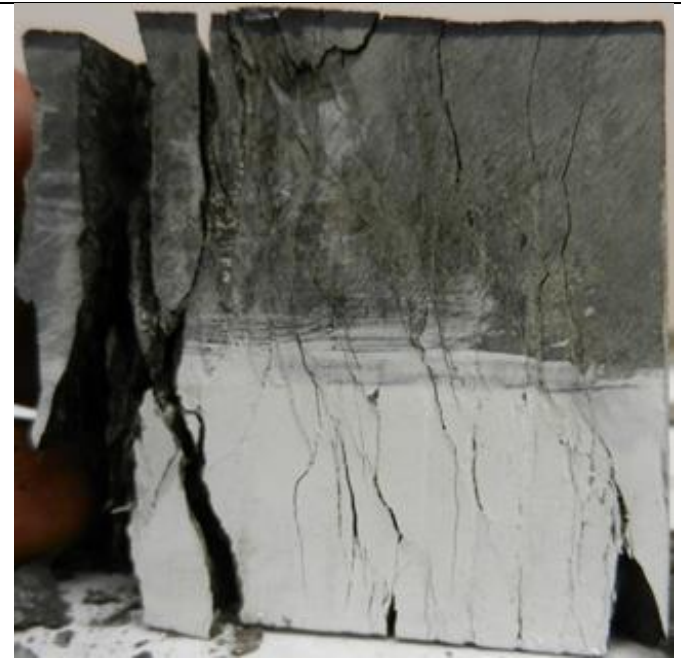

b) G7 specimen

Figure 4.9 Post-test condition of tensile failure indicator (cracks in the white marked area represents the splitting or tensile failure developed during the test) 
For verifying the movement of the lamination and failure at the same time, three specimens were selected and the entire test process was throughly recorded using a digital camera. The camera was placed at an angle to the specimen for capturing the deformation of the unconfined zone and also the movement of the laminated layers. In Figure 4.10, the photographs from only one specimen are provided.

From frame 1-12 in Figure 4.10, the boxed regions indicate the area for the development of the crack and movement of the outer layers. From frame 9-12, crack closure on the edge of the specimen and bending of the outer layer was observed. Before failure occurs, the outer rock layer showed significant deformation. Similar behavior was recorded in additional tests, verifying the fact that the lamination movement and bending occurs at the same. From these tests, we also observed that when the load is transferred from the outer edge to the inner zone of the specimen, the laminated layers also fail and small micro laminations are developed in the specimen. These inner layers then fall off when the outer layer is completely removed.

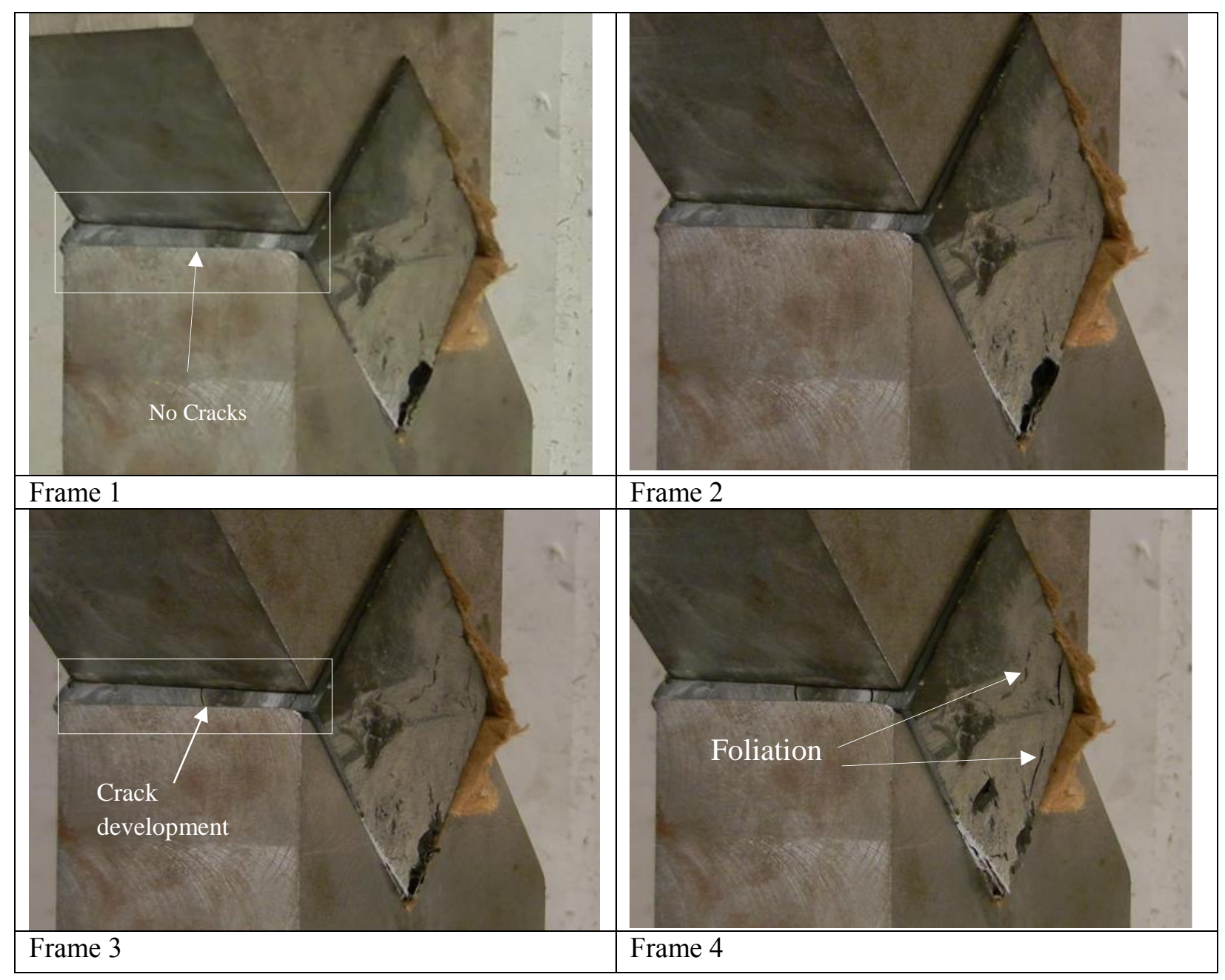




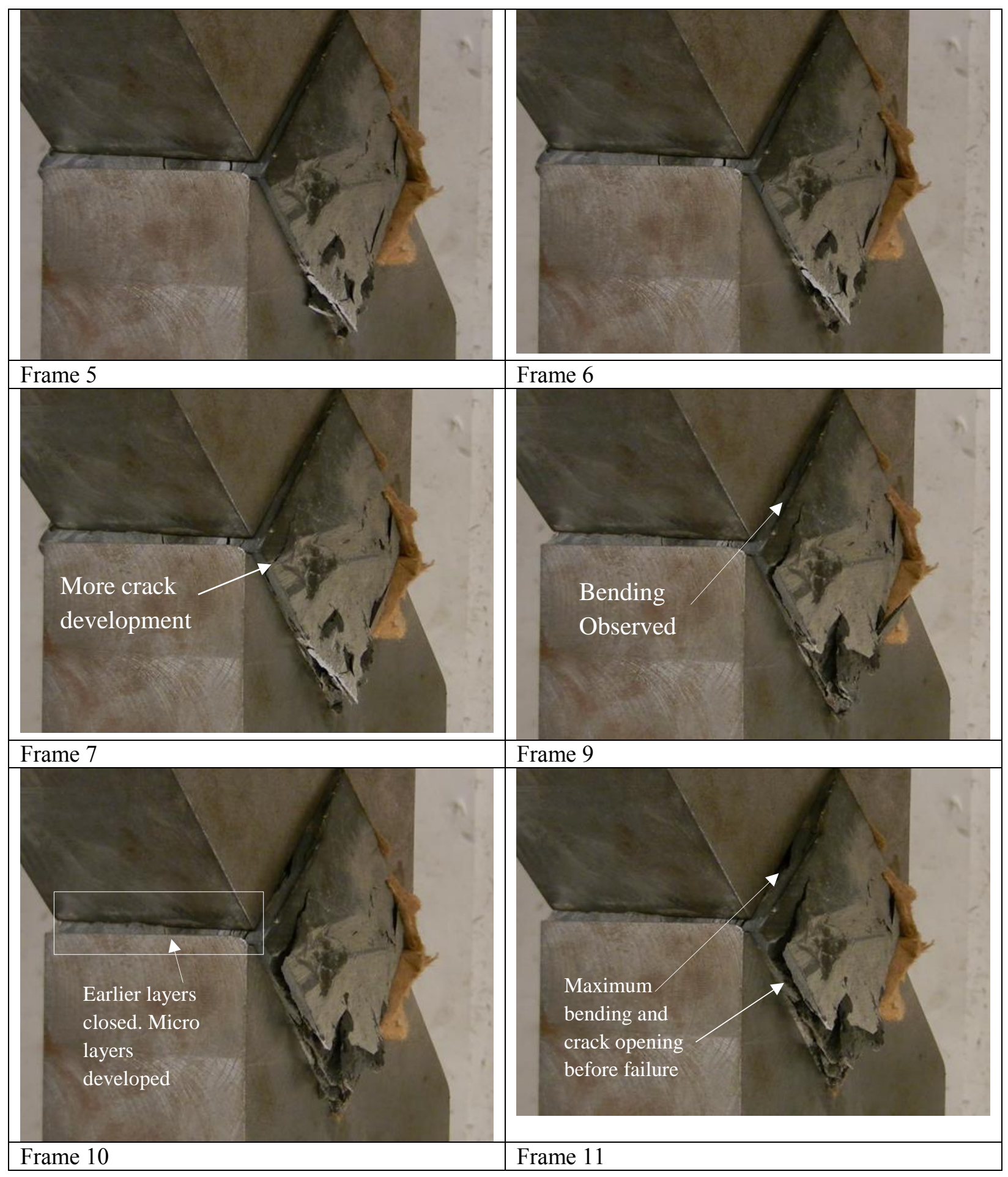




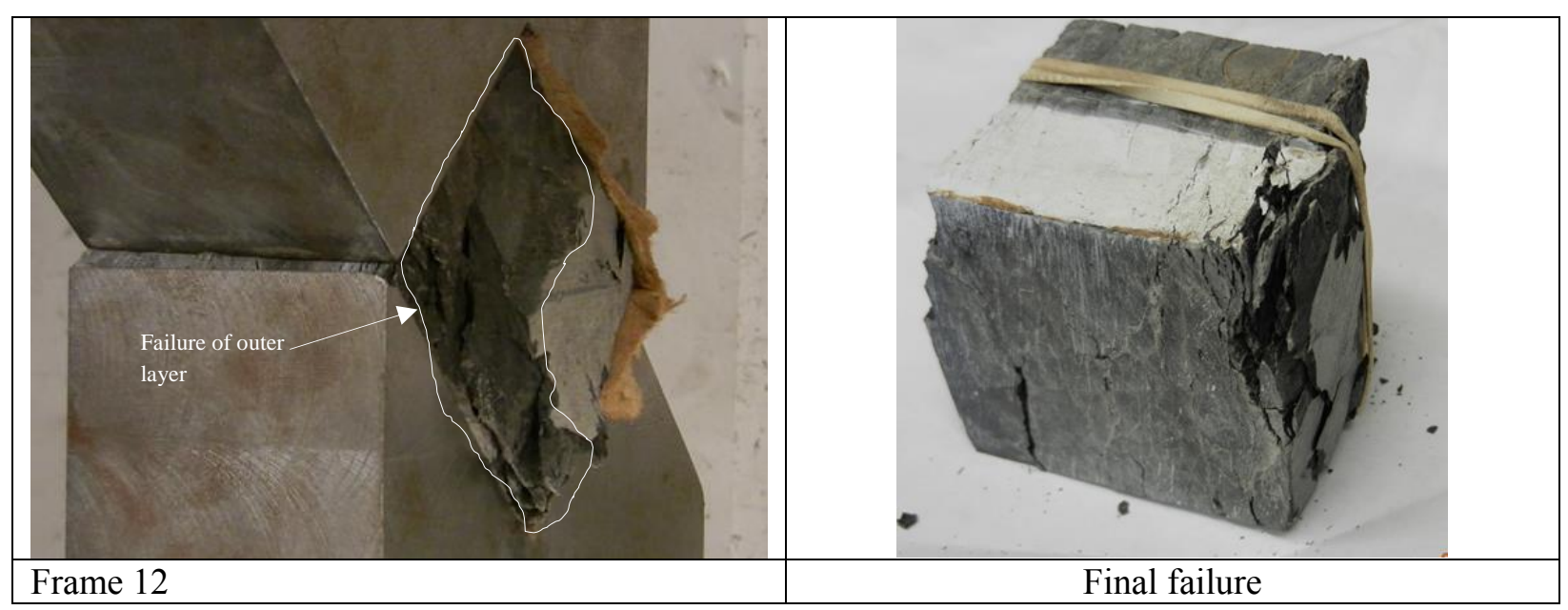

Figure 4.10 Separation of the laminated layer and crack development in the laminated specimen (Frames $1-12)$

\subsubsection{Effect of Biaxial load on limestone}

In the earlier sections, the movement of the laminated layer was observed both in the post-test state and through the movie frames. To further verify that such movements and failure of the specimen was not an artifact of the platen, limestone specimens were tested. The two inch cubical specimens were prepared from three inch cylindrical cores. The mode of failure was different from the shale specimens. These specimens failed violently, ejecting the rock chunks (Figure 4.13). In all the specimens, the core remained intact with no signs of fractures or splitting. Although the specimens first failed near the unconfined zone due to lateral expansion, the inner zone of the specimen remained intact and failed when their strength was exceeded. This behavior was evident from the plots of axial force against displacement, which showed strain softening in the post-failed stage. Consistent strain softening behavior (Figure 4.14) was observed for all the specimens except for the last where the loading had to be stopped to prevent the two platens of the biaxial device contacting with each other and causing damage to them. 


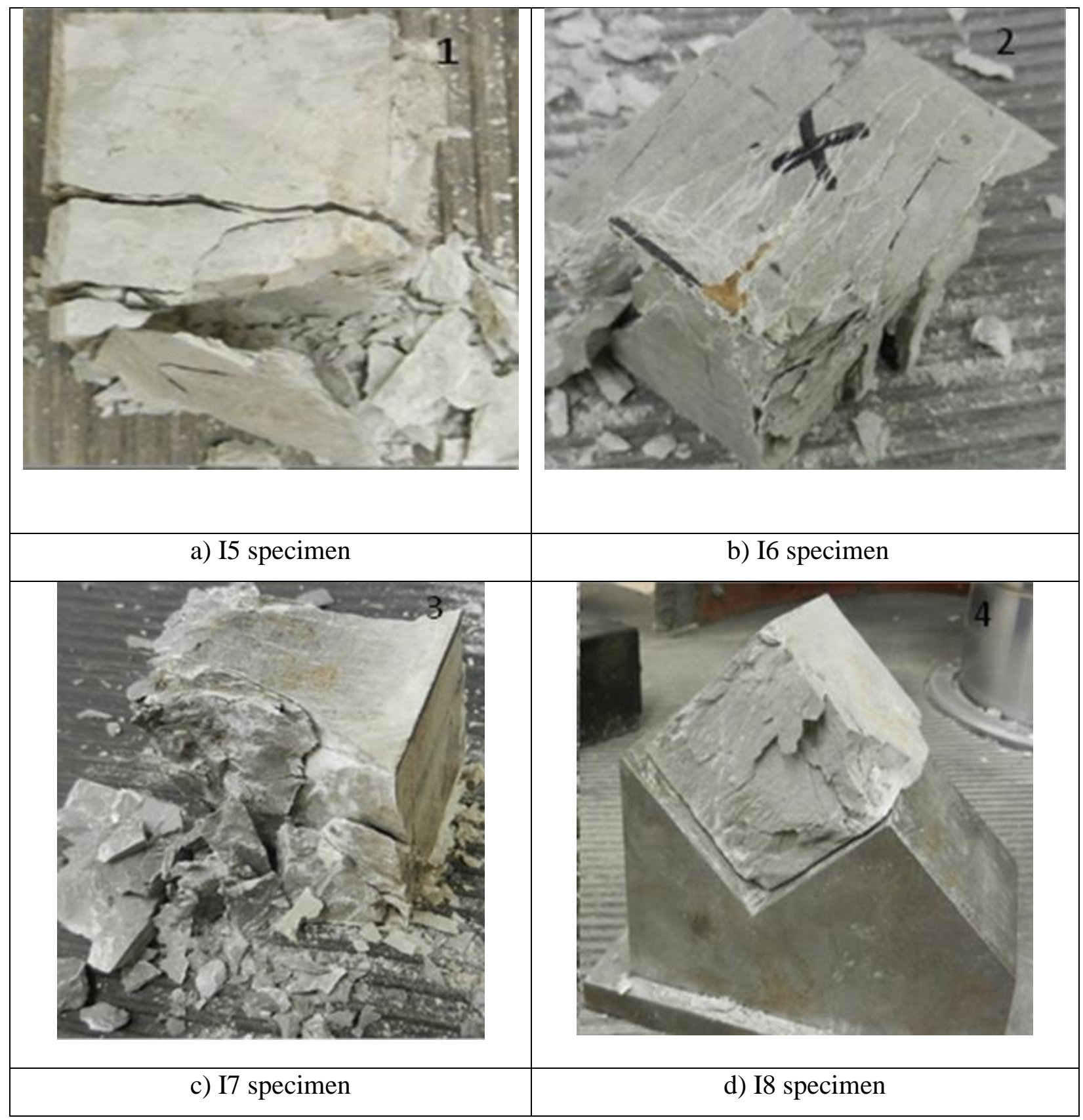

Figure 4.11 Post-test state of limestone specimens tested in the biaxial platens 


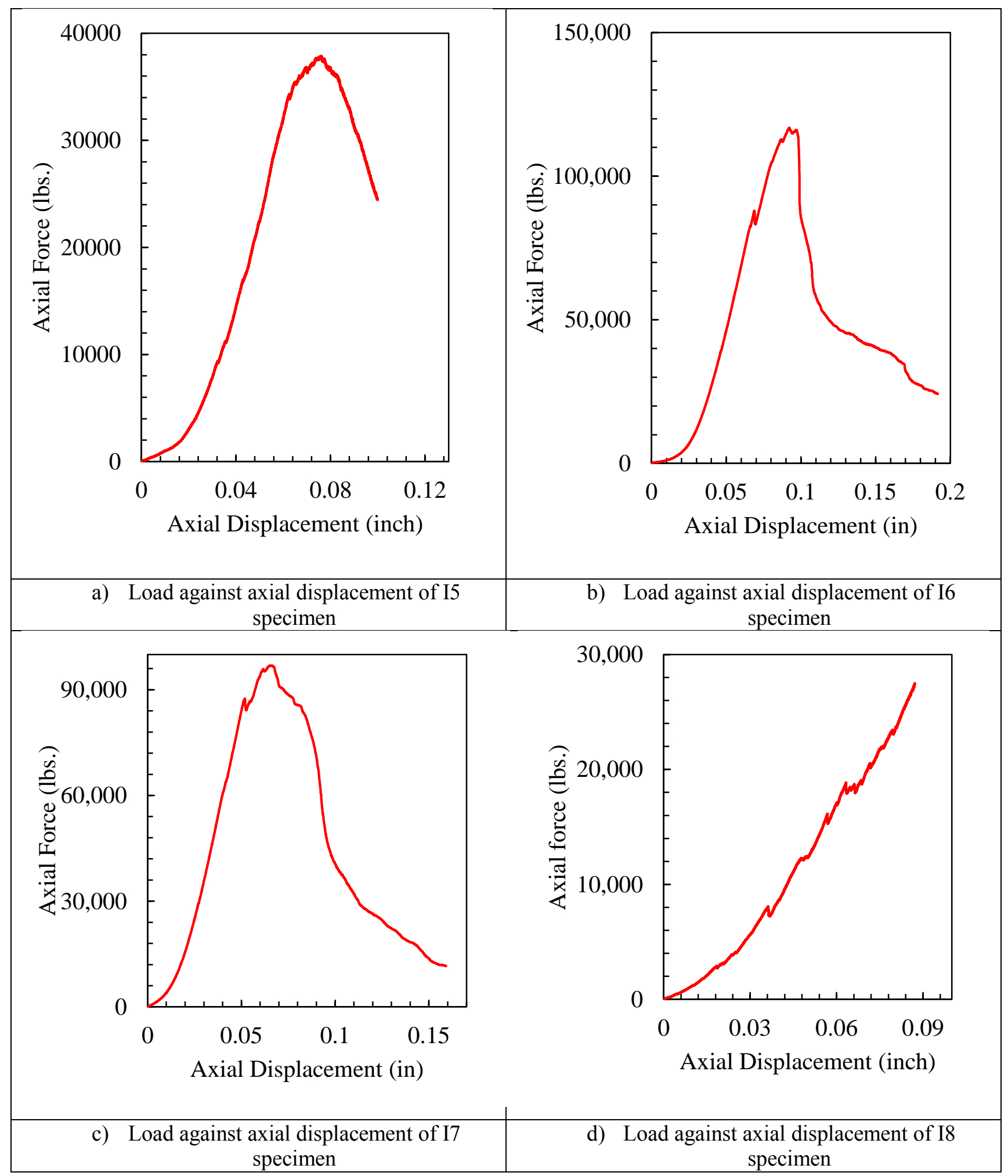

Figure 4.12 Plot of load against displacement of limestone specimens 


\subsection{Effect of triaxial loading on the laminated rock}

Biaxial tests in earlier sections showed the movement and failure of the laminated layers in laminated shale specimens. It was also shown that when limestone specimens replaced a shale specimen, there was a change in the mode of failure of the specimen. Finally, confinement was applied to the laminated specimens to observe their modes of failure.

"Pseudo triaxial" load conditions were created by confining the exposed surfaces of the specimen with the help of metal plates pressed against the specimen by c-clamps (Figure 3.7). The plates were placed on the platens instead of the specimen, which allowed unrestricted movement of the platen in the axial direction. All the specimens were tested under stroke-control mode, which allows for controlled failure of the specimen.

In Figure 4.14a, at 0.09inch displacement there is a drop in the force-displacement curve indicating failure of a section in the specimen. That is followed by rise in the curve, and the maximum load attained was 53,000 lbs. For the second specimen (Figure 4.14b), the specimen showed a non-linear force-displacement curve, which then dropped sharply at 46,000 lbs., indicating failure of the specimen. Because of the confinement, the specimen was able to sustain further load on the specimen. In the third specimen (Figure 4.14c), the specimen showed a nonlinear force-displacement curve that plateaued at 47,000 lbs., followed by a further rise in the force-displacement curve. When the laminated rock is confined, the response of the rock is similar to the non-laminated intact rock. For the fourth specimen, the axial force-displacement relationship was non-linear and plateaued at 54,000 lbs., beyond which the test was terminated.

From the tests mentioned above, it was verified that confinement reduces the influence of the lamination and the specimen shows behavior similar to an intact rock. This restrained the movement of exposed surfaces and development of localized failure near them. However, confinement induced a change in the mode of failure and the presence of lamination did not seem to have any effect on it. Confinement suppressed splitting, forcing the rock to fail in shear. The sheared zones are easily identified in two specimens that failed along conjugate shear planes (Figure 4.13 (b), (c) and (d)). This type of failure was earlier reported by Paterson and Wong, (2005) where under certain confining pressure the rock was found to be at the cusp of brittleductile transitions. It was also observed that the movement of the lamination-bending and failure of the specimen - was unique to the material and not an artifact of the load system. 


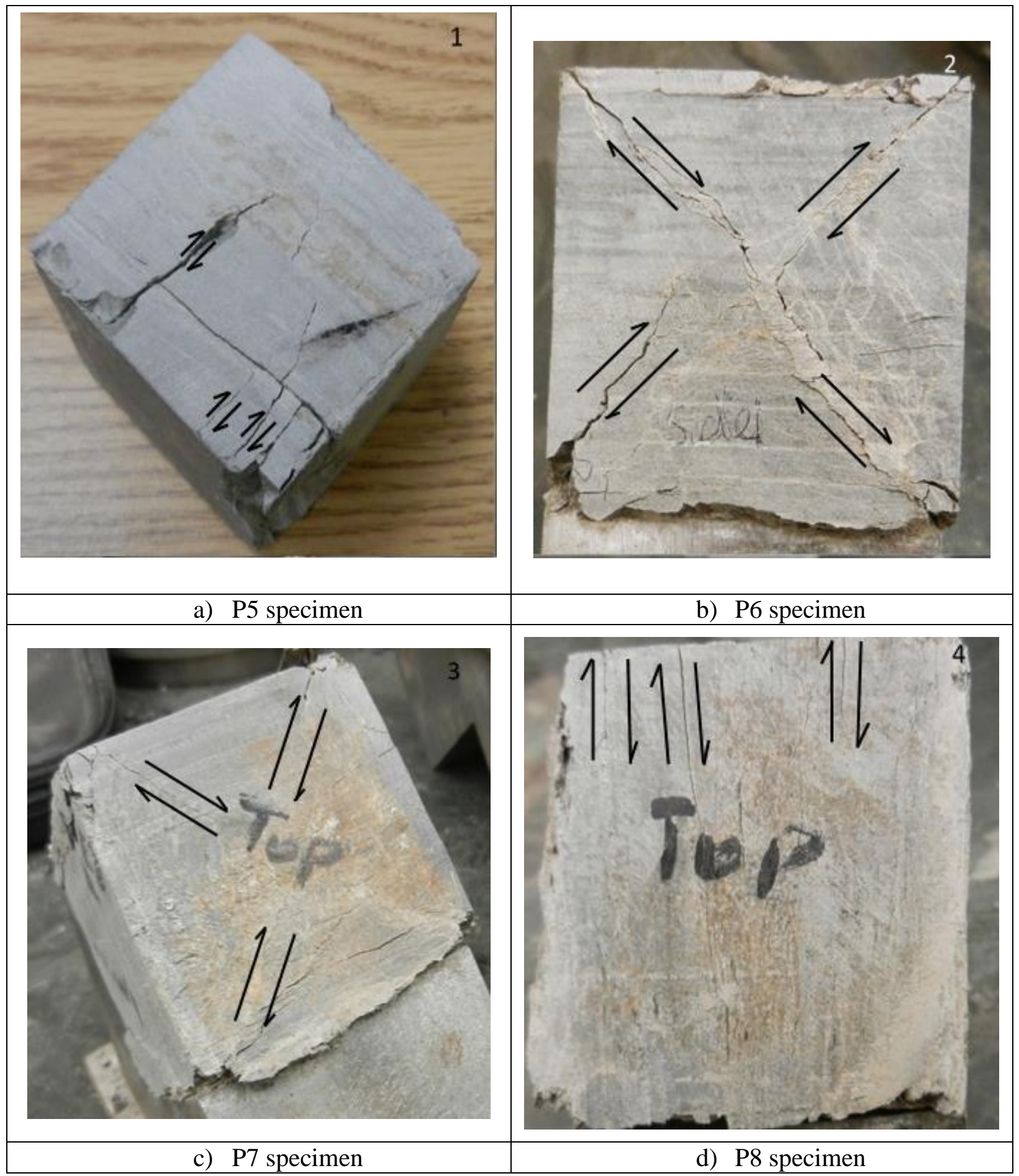

Figure 4.13 Shear failure observed in triaxial compressive test on laminated shale specimen (The side of the specimen of which pictures are presented above and the orientation of laminations same as shown in Figure 4.2) 


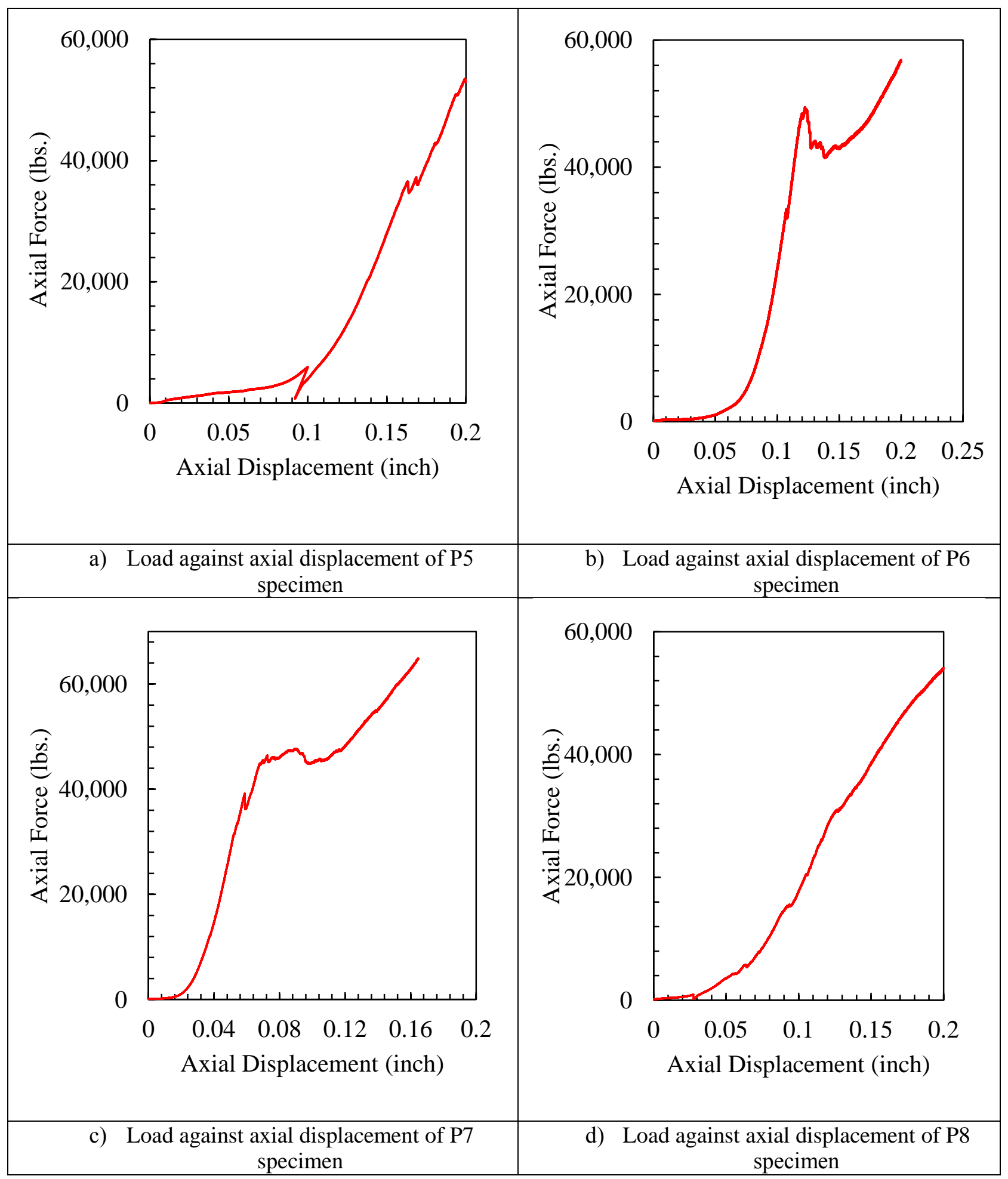

Figure 4.14 Axial force against displacement graph of the laminated shale specimens tested in triaxial compressive loading condition 


\section{Chapter 5}

\section{Summary and Conclusions}

The main objective of this research was to understand the behavior of the coal mine shale rocks under the effect of biaxial and triaxial stresses. Horizontal in-situ stresses that are biaxial in direction are known to increase the propensity of cutter type failure in the immediate roof. Laminated shale, in particular has been found to be prone to cutter-related roof falls. In-situ observations have highlighted the failure pattern in which the laminated layer fails and how the failure progresses into the upper layers of the immediate roof. Our understanding of the mechanism behind this unique failure mechanism has been limited to the numerical models which have treated the layer as a "continuum". Additionally, strain-softening behavior is typically used without fully understanding the mechanistic behavior and the mode of failure of these rock types. Therefore, it is imperative that the failure mechanism of these rock types are investigated under different stress conditions to bring forth the underlying mechanism behind such failure. This thesis attempts to shed light on this area by testing the shale rocks in biaxial and triaxial stress conditions.

A biaxial device was fabricated that applied equal stresses on four faces of the specimen. In the triaxial tests, the third dimensions of the specimens were confined using a fixed c-clamp. Samples were collected from mines located in the Pittsburgh, Illinois No. 6 and No.2 Gas seams. The samples constituted three rock types (1) Black Shale (2) Laminated Shale and (3) Limestone. From these samples, cubic specimens were prepared that were tested in the biaxial platens.

The outcomes of the test on 23 specimens are summarized in Table 5.1. The black shale specimen showed extreme brittle type failure. The failure mode in the four specimens of the black shale were characterized by the ejection of rock chunks and the progressive failure of the specimen from the unconfined surface to the center of the specimen. For the four laminated shale

specimens, the failure was marked by the bending and separation of the outer layers and the subsequent closure of the inner layers. It was also found that there was no shearing between the 
laminated layers at the macro level. The four limestone specimens tested in the biaxial device showed violent failure from these results. It was concluded that the failure mode was not an artifact of the biaxial platen but an inherent property of the rock type and stress field. Finally, four laminated shale specimens were tested under triaxial stress and showed conjugate shear failure validating the fact that each rock type has different mode of failure for given stress conditions.

The main contributions of this thesis are discussed in the following:

- Biaxial stress fields on the non-laminated shale specimens show brittle failure mode. The specimens failed at low stress conditions that match the field observations.

- Laminated shale under biaxial stress condition showed bending failure accompanied by movement of the laminated layers towards the unconfined ends. It was concluded that the presence of localized stresses induced separation between the laminated layers.

- The laminated layers did not undergo any shearing at the macro-level. When the rock layers failed at the unconfined ends the load was transferred on to the inner layers which prevented them from shearing against each other.

- The mode of failure is dependent on the rock type. Limestone specimens under biaxial stress showed failure mode which was different from the black and laminated shale specimens.

- The failure mode is also dependent on the stress conditions. Laminated shale under triaxial stress showed conjugate shear failure. The lamination effect on the mode of failure was negligible under confined conditions and the rock behaved as an intact rock. 
Table 5.1 Summary of biaxial and triaxial test results

\begin{tabular}{|c|c|c|c|c|c|}
\hline & $\begin{array}{l}\text { Specime } \\
\text { n Name }\end{array}$ & Rock Type & $\begin{array}{l}\text { Peak Load } \\
\text { (lbs) }\end{array}$ & $\begin{array}{l}\text { Approximate } \\
\text { Peak Stress } \\
\quad(\text { psi) }\end{array}$ & Failure Modes \\
\hline & \multicolumn{5}{|c|}{ Biaxial Test } \\
\hline 1 & $(\mathrm{P} 1)$ & Black Shale & 4,009 & 708 & \multirow{4}{*}{$\begin{array}{l}\text { Extremely brittle. Localized } \\
\text { failure close to the unconfined } \\
\text { surface of specimen. }\end{array}$} \\
\hline 2 & $(\mathrm{P} 2)$ & Black Shale & 44,778 & 7,915 & \\
\hline 3 & (P3) & Black Shale & 54,759 & 9,680 & \\
\hline 4 & (P4) & Black Shale & 36,118 & 6,384 & \\
\hline 1 & (I1) & Laminated Shale & 5,978 & 1,056 & \multirow{4}{*}{$\begin{array}{l}\text { Separation of the lamination } \\
\text { observed, possibly caused by } \\
\text { tensile failure. No shearing } \\
\text { observed at the macro level. }\end{array}$} \\
\hline 2 & (I2) & Laminated Shale & 11,403 & 2,015 & \\
\hline 3 & (I3) & Laminated Shale & 45,573 & 8,056 & \\
\hline 4 & (I4) & Laminated Shale & 9,385 & 1,659 & \\
\hline 1 & (I5) & Limestone & 37,902 & 6,700 & \multirow{4}{*}{$\begin{array}{l}\text { Core of the specimen intact, } \\
\text { severity of the failure close to } \\
\text { the exposed surface. }\end{array}$} \\
\hline 2 & (I6) & Limestone & 116,882 & 20,662 & \\
\hline 3 & (I7) & Limestone & 96,858 & 17,122 & \\
\hline 4 & (I8) & Limestone & 27,506 & 4,862 & \\
\hline & \multicolumn{5}{|c|}{ Confined Test } \\
\hline 1 & (P5) & Laminated Shale & 53,514 & 9,460 & Along multiple shear planes. \\
\hline 2 & (P6) & Laminated Shale & 56,865 & 10,052 & \multirow{2}{*}{ Along conjugate shear planes. } \\
\hline 3 & (P7) & Laminated Shale & 64,936 & 11,479 & \\
\hline 4 & (P8) & Laminated Shale & 54,145 & 9,571 & Along multiple shear planes. \\
\hline
\end{tabular}


For future work, further instrumentation of the experimental set-up should be performed to measure the actual load and deformation acting on all six sides of the specimen. This will increase the capability to monitor the response of specimens with the change in the confining pressure. Also, performing tests on large rock specimens in an appropriately sized platen will show effect of size on the failure modes and more laminations, due to the size, will more accurately represent the mine roof. The biaxial platen applies equal stresses to the four sides of the cubic specimen which may not always represent the in-situ stress conditions. Therefore, these tests should be performed in true triaxial load frames that are capable of applying independent stresses on 3-sides of the specimen. Different loading paths and independent stress application might produce more realistic behavior of the specimen which are not captured by the biaxial device. 


\section{References}

1. Aggson, J. R. and Curran, J., (1978), "Coal Mine Control Problems Associated with a High Horizontal Stress Field", Presentation at Annual SME Meeting, Denver, CO, USA, $19 \mathrm{pp}$.

2. Ahola, M. P., et al., (1991), "Application of Numerical Modeling Techniques to Analysis of Cutter Roof Failure," US Department of the Interior, Bureau Mines, IC9287.

3. Bajpayee, T. S., Pappas, D. M. and Ellenberger, J. L., (2014), "Roof Instability: What Reportable Non-Injury Roof Falls in Underground Coal Mines Can Tell Us," Professional Safety, Vol. 59, No. 3, pp. 57-62.

4. Bauer, E. R., (1990), "Cutter Roof Failure: Six Case Studies in the Northern Appalachian Coal Basin,” US Department of the Interior, Bureau Mines, IC 9266, 18 pp.

5. Chen, H., (1999), "Stress analysis on longwall entry under high horizontal stress" Ph.D. Dissertation, West Virginia University, Morgantown, USA.

6. Dahl, H. D., and Parsons R. C., (1972), "Ground Control Studies in the Humphrey No.7 Mine, Christopher Coal Division, Consolidation Coal Co.," Trans. Soc. Min. Eng., AIME, Vol. 252, pp. 211-222.

7. Dolinar, D.R., (2003), "Variation of horizontal stresses and strains in mines in bedded deposits in the eastern and mid-western United States," Proceeding of the 22nd International Conference on Ground Control in Mining, Morgantown, West Virginia, USA, pp. 178-185.

8. Esterhuizen, G. S. and Bajpayee, T. S., (2012), "Horizontal Stress Related Failure In Bedded Mine Roofs-insight From Field Observations And Numerical Models," Proceedings of the 46th US Rock Mechanics/Geomechanics Symposium, Chicago, IL, USA, pp. 68-77.

9. Gadde, M. M. and Peng, S. S., (200)5, "Numerical simulation of cutter roof failures under weak roof conditions," Paper presented at the SME annual meeting, Salt Lake City, Utah, USA, pp. 459-469.

10. Hill, J. L., III, and Bauer, E. R., (1984), "An Investigation of the Causes of Cutter Roof Failure in a Central Pennsylvania Coal Mine: A Case Study," Proceedings of the $25^{\text {th }}$ Symposium on Rock Mechanics, Evanston, IL, USA, pp. 603-614.

11. Iannacchione, A. T., Popp J. T. and Rulli J. A., (1984), "The Occurrence and Characterization of Geologic Anomalies and Cutler Roof Failure: Their Effect on Gate 
road Stability", Proceedings of $2^{\text {nd }}$ International Conference on Stability in Underground Mining, Soc. Min. Eng. AIME, pp. 428-445.

12. Ingram, D. K., and Molinda G. M., (1988), "Relationship Between Horizontal Stresses and Geologic Anomalies in Two Coal Mines in Southern Illinois," US Department of the Interior, Bureau Mines, RI 9189, 18 pp.

13. Jumkis, A. R., and Jumkis, A. A., (1975), "Red Brunswick Shale and its Engineering Aspects". New Brunswick, N.J.: Rutgers University, College of Engineering, Engineering Research Bulletin 55, pp. 51.

14. Kripakov, N. P., (1982), "Alternatives: for Controlling Cutter Roof in Coal Mines," Proceedings of $2^{\text {nd }}$ International Conference on Ground Control in mining, Morgantown, WV, USA, pp. 142-151.

15. Mark, C., (1991), "Horizontal Stress and Its Effects Longwall Ground Control," Mining Engineering, pp. 1356-1360.

16. Mark, C., (2002), "The introduction of roof bolting to US underground coal mines (19481960): a cautionary tale," Proceedings of the 21st International Conference on Ground Control in Mining, Morgantown, WV, USA, pp. 150-160.

17. Mark, C. and Gadde, M., (2008), "Global trends in coal mine horizontal stress measurements". In: Peng SS, Tadolini SC, Mark C, Finfinger GL, Heasley KA, Khair AW, Luo Y, eds. Proceedings of the 27th International Conference on Ground Control in Mining, Morgantown, WV, USA, pp. 319-331.

18. Mark, C., Pappas, D. M. and Barczak, T. M., (2011), "Current trends in reducing ground fall accidents in US coal mines," Mining Engineering, Vol. 63, No. 1, pp. 60-65.

19. McGarr, A., (1988), "On the state of lithospheric stress in the absence of applied tectonic forces", Journal of Geophysics Research: Solid Earth, Vol. 93, No. B11, pp. 1360913617.

20. Molinda, G. and Mark, C., (2010), "Ground failure in coal mines with weak rocks," The Electronic Journal of Geotechnical Engineering (F. Bund), Vol. 15, 2010, pp. 547-588.

21. Molinda, G. M., Mark, C., Pappas, D. and Klemetti, T., (2008), "Overview of ground control issues in the Illinois Basin," SME Transactions, Vol. 324, pp. 41-48.

22. MTS reference manual, 1990.

23. Paterson, M. S. and Wong, T. F., (2005), Experimental rock deformation - the brittle field. 2nd ed. New York: Springer-Verlag. pp. 18. 
24. Peng, S.S., (2007), "Ground Control Failures - A pictorial view of case studies," S.S. Peng Publisher, pp. 83, 94, 100.

25. Ray, A.K., (2009), "Influence of cutting sequence and time effects on cutters and roof falls in underground coal mine - numerical approach," Ph.D. Dissertation, West Virginia University, Morgantown, USA.

26. Roley, R. W., (1948), "Pressure-Cutting: A Phenomenon of Coal-Mine Roof Failures," Mechanization, Vol. 12, No. 12, pp. 69-74.

27. Su, D. W. H., and Hasenfus G. J., (1995), "Regional Horizontal Stress and Its Effect on Longwall Mining in the Northern Appalachian Coal Field", Proceedings of the 14th International Conference on Ground Control in Mining, Morgantown, WV, USA, pp. 3945 .

28. Su, Wen H., and Peng, S. S., (1987), "Cutter Roof and its Causes," Mining Science and Technology, Vol.4, No. 2, pp. 113-32.

29. Zoback, M. L., (1992), "First- and second-order patterns of stress in the lithosphere: the World Stress Map Project," Journal of Geophysics Research: Solid Earth, Vol. 97, No. B8, pp. 11761-11782.

30. Zoback, M. L., Zoback, M. D., Adams, J., et al., (1989), "Global patterns of tectonic stress", Nature, Vol. 341, pp. 291-298.

31. Zoback, M. D. \& Zoback, M.L., (2002), "Stress in the earth's lithosphere", International Geophysics, 16, pp. 143-154, Academic Press, San Diego, USA.

32. Zoback, M.L. and Zoback, M.D., (2007), "Lithosphere Stress and Deformation," Chapter 6.06 in Vol. 6: Crust and Lithosphere Dynamics, Treatise on Geophysics, Elsevier, pp. 253-273. 